\title{
Evaluation of Utility Management Practice in Road Construction Projects of Mekelle City
}

\author{
Mearg Ngusse Sahle, Ashenafi Aregawi \\ Department of Construction Technology and Management, Ethiopian Institute of Technology Mekelle, Mekelle, Ethiopia \\ Email address: \\ mearg.ngusse@mu.edu.et (M. N. Sahle), ashari1998@gmail.com (A. Aregawi) \\ To cite this article: \\ Mearg Ngusse Sahle, Ashenafi Aregawi. Evaluation of Utility Management Practice in Road Construction Projects of Mekelle City. American \\ Journal of Engineering and Technology Management. Vol. 6, No. 4, 2021, pp. 47-71. doi: 10.11648/j.ajetm.20210604.11
}

Received: July 19, 2021; Accepted: July 28, 2021; Published: August 5, 2021

\begin{abstract}
Poor installation, relocation, maintenance, and management of utilities in a road right-of-way causes; (a) project delays to ongoing road construction projects, (b) repetitive damage and service loss to utilities, and (c) frequent pavement cuts to roads after project completion. This research aimed to evaluate the telecommunication, electric power and water supply utilities management practice in Mekelle city, during the life cycle of road projects, with a special emphasis to the construction phase. The evaluation was made by using 14 project success criteria parameters to measure the performance of stakeholders according to the Ethiopian standards, and benchmarking the current practice with European \& U.S.A best practices. Quantitative descriptive-survey approach followed by qualitative-case studies were used for the research. The quantitative data has been gathered using three different sets of questionnaires. Part I contained questions designed to study the pre-construction, and post-construction utility management practices. The respondents were road administrator, utility operators and urban planners. Part II and III of the questionnaire surveyed road designers and contractors for issues of utility management during road design and construction phases respectively. In order to confirm the responses from the questionnaire surveys, observations on 12 ongoing \& 6 recently competed road projects, and desk study survey of 5 ongoing road projects were made. Then the root causes of utility management problems were identified using qualitative case studies on the capacity and limitations of individual stakeholders. Based on the data analysis it is concluded that, the current practice of utility management during a road project life cycle is very poor both according to the Ethiopian standards, and in comparison to the European and U.S.A. best practices. $98 \%$ of the ongoing road construction projects suffer impacts due to delay in relocating utilities; $43 \%$ of the contractors suffered frequent costs of utility damages; and $95 \%$ of the recently completed roads suffer from inadequacy of ROW, road-utility conflicts, and non-uniform utility installation practice. The root causes to the utility management problems are (1) inadequate or nonexistent standard guidelines, (2) lack of technology and knowledge for utility management, (3) absence of integrated infrastructure planning and development, and (4) absence of asset management program among the infrastructure planners and operators in Mekelle city.
\end{abstract}

Keywords: Utility Relocation, Utility Cut, Utility Management, Integrated Road-Utility Management

\section{Introduction}

Utilities such as electric power, telecommunication, water supply and sanitary sewer lines are routinely placed in a highway Right-of-Way (ROW) in order to minimize land acquisition requirements, disruption, and costs. As a result, they are especially susceptible to relocation and rupture during urban road improvement or bridge replacement projects. Hence, they require special precautionary arrangement; as they could cause delays that can extend road project delivery, disruptions when utility lines are encountered, and inadvertent repetitive damage to the utilities during construction [1].

It is common to experience delays during road construction projects due to road-utility conflicts. Different studies commissioned by the United States - National Cooperative Highway Research Program (US-NCHRP) held utility relocations to be number one root cause responsible for highway construction project delays in the United States [2, 3]. In India only utility relocation was the major cause of significant delay for every one out of five National Highway Development Program Projects [4]. Similar studies in Srilanka [5] and Ghana [6] also ranked utility relocation to be the 
second highest factor causing project delays. In general utilities removal, relocation, or adjustment causes disruptions, inefficiencies and delay costs to road projects. Furthermore, contractor crew are more susceptible to risks of accidents when they encounter a sudden burst of pipes, cable snaps or gas leaks during excavation.

Utility lines are often buried in the ground at shallow depth; as a result they are often discovered during excavation activities. Hitting one of these services when carrying out an excavation by either puncturing or damaging the sheath or protective wrap is termed as 'Utility Strike' [7]. Utility strikes cost both the utility industry as a whole and society in general through interruption of public services, public capital loss due to amendments for punctured public utilities, and insurance claims. Utility strikes are the result of out-of-date information on the existence and location of subsurface utilities [6, 7].

Although the biggest challenges of public utility management are not technological but organizational; the need for accurate mapping is also inevitable [9]. Inaccurate, incomplete, and/or out-of-date information on the existence and location of existing utilities reduces the engineers', owners', and contractors' abilities to make informed decisions and to support risk management decisions regarding the project's impact on existing utilities [8]. Besides, accurate utility information is critical for the identification of conflicts among highway design, existing utility facilities, highway construction activities, and safety regulations [1].

Generally utility relocations during urban road construction projects face both management and design issues. These issues are routinely handled through change orders, extra work orders, insurance payouts, and contingency pricing [8]. Thus, there is a need for standardized utility management system in road projects. The need for cost-effective collection, depiction, and management of existing utility information is also inevitable. To allow for the adoption of cost effective solution strategies an integrated planning, design, construction, and management are required.

After road project completion, uncoordinated utility management causes frequent pavement cuts for utility maintenance works, and difficulty to locate \& manage the utilities. Existing utilities deteriorate and require repair or replacement during the post-construction phase of a road project life cycle. This causes for roads to be excavated repeatedly by a procession of different organizations. Subsequently returning the road to its original state becomes a difficult task; hence the overall road life expectancy and serviceability is declined [10]. Besides, poor re-installment of utilities causes high surface roughness and deformation of roads [11]. Generally disorderly repetitive excavation of streets is responsible for damage to other utilities, uneven pavement surfaces, annoyance to drivers, diminished quality of street works, and further pavement maintenance costs [12-14].

All stakeholders are affected due to lack of coordination and planning of utility management during a road project life cycle. The client and contractors are subjected to disruptions, conflicts, risk of accidents, costs of delay, and road repair. Likewise utility owners experience costs of repair of ruptured utilities, loss of income, claims, and difficulty of managing utilities. Above all public interests of quality \& uninterruptible utility services, minimized loss of business income, reduced public capital loss, quality street works, and fewer traffic accident rates are compromised.

Public utility adjustment and relocation requires numerous permits from various government authorities necessitating constant liaison between all stakeholders [4]. As a result, great deal of planning and coordination is crucial during life cycle of a road project. This could be done by creating a framework and communication platform that fosters the necessary collaboration under mutual benefit of all stakeholders [15].

Most road projects encounter utility conflicts at least in their section passing through towns \& cities. According to the Ethiopian Road Authority geometric design manual, all highway improvements whether within the existing ROW or entirely on a new ROW, generally entail adjustment of utility facilities [16]. Thus, it is important that every effort be made to identify all utilities that may impact a highway improvement project; because they can be a major consideration both in the design and cost of the improvement project [17].

Regarding highway improvement projects $114 \mathrm{Kms}$ of trunk roads were rehabilitated, $764 \mathrm{Km}$ of trunk roads \& link roads were upgraded, and $714 \mathrm{Kms}$ of new link roads were constructed only during the first year of Road Sector Development Program - Phase V (RSDP V) [18]. The RSDP $\mathrm{V}$ plans to construct a total of $104,586 \mathrm{Km}$ of road by the end of 2020 [19]. The Growth and Transformation Plan Phase II (GTP II) also plans to expand electricity service coverage to $90 \%$, telecommunication density to $54 \%$, and water supply coverage to $83 \%$ country wide [20]. The GTP II plan implementation in $2017 / 18$ fiscal year was lower only by $3.4 \%$ than the target set [21].

According to the 2017/18 annual report of the National Bank of Ethiopia, total road network in Ethiopia has reached $126,773 \mathrm{Km}$, showing a $5.5 \%$ annual expansion [22]. The report also added that, asphalt road network accounted for about 12.5 percent of the total road network which was slightly lower than 14.5 percent GTP II target set for the fiscal year. The telecom density was also $43 \%$; which is $11 \%$ lower than the GTP II target plan [22].

The above figures confirm that transportation and utility networks are continuing to grow in complexity and size in Ethiopia. Since road \& utility networks occupy a common ROW the likelihood of conflicts necessitating relocation of utilities during road construction projects will be amplified. Besides, both road project delays and frequent pavement cuts are problematic in Ethiopia. Studies by Koshe and Jha revealed that $91.75 \%$ road projects in Ethiopia have been delayed $352 \%$ of their contractual time [23]. In addition, $44 \%$ of Addis Ababa city roads severely suffer from frequent pavement cuts, and lack of proper maintenance [24]. Although Ethiopian literatures on pavement cutting and repair are scarce; this is a good indicator of utility management problems. Therefore, the need for a standardized utility management system in the Ethiopian road projects is inevitable. 
Because utilities are one part of road ROW, the management of utility relocation, adjustment, and maintenance during road construction projects is a well-studied subject throughout the world. Accordingly, several studies have identified utility related problems $[3,7,9$, $10,12,13,15]$.

However, despite the complexity and growth in road and utility networks in Ethiopia [20-22], and challenges of road delays and frequent pavement repairs [23, 24] little consideration is given to the concerns of locating, coordinating, relocation, repair, and management of utilities. There are no separate Ethiopian standards and regulations that clearly identify a strategic framework for the management, installation, relocation, and maintenance of utilities. Literatures identifying issues of utility management and their solution in the Ethiopian context are also scarce. As a result, utility related concerns in Ethiopia are yet to be studied and remain unresolved.

Project delays, utility strikes, service loss and pavement cuts are conspicuous in the Mekelle city road projects. Besides, there are frequent utility relocations caused due to lack of planning and integration among infrastructure offices. For instance, the relocated telecommunication poles in the Zesselassie square - Elala road project were installed during the topographic survey stage of the road. However, efforts made by the road design consultant to avoid relocations of the poles were unsuccessful. Similarly, utilities requiring relocation in the ongoing Mekelle-Samre Road to Abune-Aregawi Lachi Church project were installed two years prior to its commencement.

In order to avoid this enormous wasteful use of scarce resources, the root causes of utility management problems during all phases of road development, with a special emphasis to the construction phase, need to be studied by involving urban planners, utility operators, road designers and contractors.

The general objective of this research was to evaluate the public utility management practice during urban road construction projects in Mekelle city. The specific objectives were;

a) To assess the management practice of urban utilities like telecommunication networks, electric power cables or poles, and water supply pipes during urban road construction in Mekelle city.

b) To evaluate the current utility management practice by using the existing laws, standards, and approved practices as a benchmark.

c) To identify the root causes of current utility management problems during urban road construction projects in Mekelle city.

\section{Literature Review}

\subsection{Utility Management in the Road Construction Industry}

The construction industry is a vital component of the world economy. Rapid growth of construction projects have benefited mankind by providing social requirement like infrastructure, building etc. as well as contributing significantly in the economic growth of a country [25]. Especially in developing countries the construction industry remains so with the continuation of the development process. However, it is challenged by poor performance arising from existing practices [26]; alongside with the general situation of socio-economic stress, chronic resource shortages, institutional weaknesses, and a general inability to deal with the key issues [27].

Road construction requires the creation of an engineered continuous ROW overcoming geographic obstacles. This ROW is also commonly occupied by utility networks in order to minimize land acquisition requirements, disruption, and costs. When road and utility management are not well coordinated, the public, utilities and road contractors suffer delays and extra expense [28]. Issues regarding the location, coordination, and relocation of utility facilities are a growing concern among public administrators, utility operators, construction contractors, and designers. Improved coordination among these four entities is needed to reduce project delays, conflicts, safety risks, traffic congestion and added inconvenience and expense to taxpayers, motorists, contractors, utility operators, and adjacent property owners [29].

\subsection{Problems of Utility Management in Road Projects}

Poor installation, relocation, maintenance, and management of utilities in a road ROW causes; (a) project delays to ongoing road construction projects, (b) repetitive damage and service loss to the utilities, and (c) frequent pavement cuts to the roads after project completion.

Lack of project and utility coordination is responsible for $43 \%$ of delays even in a developed country like the United States of America (US) [30]. A survey done on state highway agencies, contractors and consultants to study the root causes of delays in highway construction projects concluded that; unidentified and incorrectly located utilities are the number one root cause of delays and cost overruns of highway projects in the US [2, 31]. The South Carolina Department of Transportation also studied 22 multi-million dollar construction projects, in order to reduce project delays by $25 \%$ [32]. Although the study parameters were confined only to the construction phase, it was found out that utility relocation caused $21 \%$ of all construction delays in South Carolina. In India only utility relocation was the major cause for significant delay of 44 out of 224 National Highway Development Program Projects [4]. Similar studies in Srilanka and Ghana also ranked utility relocation to be the second highest factor $[5,6]$.

Utilities are also inadvertently damaged during excavation as a result of out-of-date information on their existence and location. This costs both the utility industry as a whole and society in general through interruption of public services, public capital loss due to amendments for punctured public utilities, and insurance claims [8].

Repetitive excavation of roads causes 4 million holes to be 
dug every year in the United Kingdom (UK); which costs 5.5 billion Euros annual economic damage [7]. Another study that determined the level of impact of utility cuts on the serviceability of pavements in Calgary, Canada also estimated $22 \%$ loss of service life of pavements due to utility cuts [10].

\subsection{Main Causes of Utility Management Problems}

Many researchers believe that, the two critical factors that contribute to utility management problems are (a) lack of accurate, complete information about utility facilities that might be in conflict with the road project, and (b) insufficient coordination \& communication among stakeholders to resolve and manage those conflicts [2, 5, 6, 31-34].

A study on the Texas Department of Transportation highway improvement projects, concluded that the lack of adequate information about the location and characteristics of utility facilities can result in a number of problems, including damages to utilities, disruptions to utility services, service loss of utility facilities and delays to highway projects [33]. A survey done on state highway agencies, contractors and consultants of the US to study the root causes of delays in highway construction; found out that unidentified and incorrectly located utilities to be the number one root cause of delays $\&$ cost overruns of highway projects $[2,31]$.

Utility strikes happen once in every 60 seconds in the US causing billions of dollars cost of utility damage annually [35]. A study assessed the impact of utility strikes and their true costs by detailing 16 case studies of utility strikes in Britain [7]. The site staff of the studied cases claimed that large portion of utility strikes are experienced as a result of outdated statutory records, poor utilities information, or in some cases none at all.

According to the above studies, lack of adequate information on the location of existing utilities, and lack of effective coordination and communication among stakeholders are the main causes of utility management problems.

\subsection{Approved Practices for Utility Management}

\subsubsection{Integrated Road-Utility Mapping}

An integrated, reliable road-utility mapping is crucial to achieve well informed planning decisions, and manage utilities during road construction projects. Integrated road-utility maps result in systems integration, elimination of paper maps, centralized updates of maps, greater efficiency, better decision making, improved communication, and better record keeping practices. A range of two dimensional such as Aeronautical Reconnaissance Coverage Geographic Information System (ArcGIS), Infrastructure for Spatial Information in Europe (INSPIRE) $\}$, and three dimensional \{such as City Geoscience Markup Language (CityGML), Industry Foundation Classes (IFC) \} utility network models have been developed for storage, visualization, exchange, and analysis of utility data.

The ArcGIS utility model provides a GIS-based utility solution to represent the underlying logical and physical relations of utility networks [36], and the INSPIRE utility networks model defines the basic application schema of utility networks in a city or country range [37]. However, these models focus only in $2 \mathrm{D}$ representation, without $3 \mathrm{D}$ geometric information of utilities. Certain studies contend that 2D models cannot precisely present multidimensional and dynamic spatial phenomena [38, 39].

A 3D map of utility networks can provide a reliable and accurate information on underground utility networks that can lead to a better understanding and management of underground space [40]. The CityGML utility network focuses mainly on the representation of topographical, graph structural and functional information across the multi-utility networks in a 3D space $[41,42]$. This data model not only represents a utility network component by its $3 \mathrm{D}$ topography and complementary graph structure [41], but also considers interdependencies between utility network features and city objects [43]. The IFC utility model, pays more attention to the supply service of buildings in the civil engineering and architecture domain [44]. It describes 2D and 3D geometry of utilities within a building and the logical or physical connection between building service components. In order to provide utility data for 3D visualization and other applications, it is necessary to integrate different types of utility datasetsfrom multiple surveying methods.

In addition, few existing works consider the $3 \mathrm{D}$ cadaster application for underground infrastructures [45, 46]. They recommend the integration of subsurface utility networks in urban land tenure systems.

\subsubsection{Utility Information Management}

Utility information management necessitates for an efficient data collection, depiction, management \& distribution systems to be utilized by all stakeholders. Subsurface Utility Engineering (SUE), Public Utility Database, Electronic Mark Plant Circulation system (EMPC), and One-Call notification center are among the current practices used for the collection, management and distribution of data among stakeholders.

SUE is one of the tools used for the collection and depiction of existing overhead \& subsurface utility information; since existing records are often inaccurate or incomplete [3, 47]. Itmanages risks associated with utilities via utility conflict resolution during design, utility coordination, and estimating utility relocation costs $[1,48]$.

SUE encompasses surface geophysics, surveying techniques, computer-aided design, geographic information systems, and minimally intrusive excavation techniques [8]. The American Society of Civil Engineers, British Standards Institute and the Mainroads Western Australia have developed standard guidelines for the collection and depiction of existing subsurface utility data (ASCE 38-02; PAS 128: 2014; Underground Utilities Survey Standard 67-08-121) [8, 49, 50]. These standard guidelines describe four quality levels of utility depiction:

a) Quality Level D - Data Quality: Information derived 
solely from existing records or verbal recollections.

b) Quality Level C - Planning Quality: Information obtained by surveying and plotting visible aboveground utility features and by using professional judgment in correlating this information to Quality Level D information.

c) Quality Level B - Design Quality: Information obtained through the application of appropriate surface geophysical methods to identify the existence and approximate horizontal position of subsurface utilities. "Quality level B" data are reproducible by surface geophysics at any point of their depiction. This information is surveyed to applicable tolerances and reduced onto plan documents.

d) Quality Level A - Construction Quality: Information obtained by the actual exposure (or verification of previously exposed and surveyed utilities) of subsurface utilities, using minimally intrusive excavation equipment to determine their precise horizontal and vertical positions, as well as their other utility attributes. This information is surveyed and reduced onto plan documents.

There are several surface geophysical survey techniques that are used for underground utility detection during Quality level B-SUE. These techniques such as electromagnetic waves, mechanical waves, Electricity resistivity methods, Magnetic methods, Micro-gravitational methods, and Chemical methods minimize the need for test holes.

SUE provides many benefits by reducing unnecessary utility relocations, utility conflicts, delays to projects, contractor claims, and redesign costs. In 2005, the University of Toronto published a 12 month study to investigate the practice of utilizing SUE on large infrastructure projects in Ontario. The report included detailed documentation of 9 cases having a large number of buried infrastructure systems. For these particular cases, the average return-on-investment for SUE was approximately $\$ 3.41$ for each \$1 spent [51]. Similarly in 2007, an in-depth 12 month study was done by Penn State University on ten randomly selected Pennsylvania Department of Transportation projects. The study revealed $\$ 22$ savings in total project cost for every $\$ 1$ spent in quality level B or quality level A SUE [52].

Public utility database is a centralized database, requiring an expensive initial investment to store and archive all as-built utility records. For example, New York City have got GIS-based system to manage the city infrastructures [53]. In the study conducted to develop a framework for effective management of underground utilities; existing utility information database, 3D GIS data inquiry, and clash analysis were evaluated [14]. A conclusion was made that, although cities like Hong Kong, Shanghai and Tianjin have tried to establish centralized databases; most of these databases become untrustworthy as they fail to provide effective mechanism for editing and updating as-built records.

Data distribution is facilitated through a common information sharing platforms such as EMPC and One-call systems. Both EMPC and One-call systems themselves will not store any data but serve as information exchange platforms. Electronic Document Delivery (EDD) or EMPC is the use of electronic files to communicate highway project design information and status over the internet to affected utility owners.

Transferring files using Hypertext Transfer Protocol (HTTP) and e-mail is also a common practice. However, both HTTP \& e-mail do not provide fast and efficient transfer of large files. Subsequently, EDD using a File Transfer Protocol (FTP) site is being applied for file transfer [54]. For instance, Georgia Department of Transportation uses Utility Redline Software that facilitates the transmitting of utility plan markups in electronic format [88]. In Hong Kong, EMPC works as a platform for different utility companies to circulate as-built information [55]. Companies send request for information, drawings, and letters through emails that are directed to an EMPC server. Thus any other companies that have existing properties in this specific area, which is located using GIS, will send their as-built records to EMPC, and then to this company with new applications.

One-call notification center is another efficient stakeholder communication platform that helps excavators to make informed decisions. It prevents damage to utilities. For instance, most states in the United States employ a statewide notification center that provides contractors, homeowners, and others who may be disturbing the earth, with a single toll-free number to call for the locating and marking of underground facilities [54, 56-59]. Australia employs a similar mechanism 'Dial-Before-You-Dig' call center which also has a website to submit requests online [60].

\subsubsection{Coordination, Communication, Cooperation}

Effective Coordination, Cooperation and Communication (CCC) among stakeholders is of significant importance to reduce project delays, conflicts, safety risks, and added inconvenience \& expense to all stakeholders. Many literatures concluded that the CCC management approach to be the approved practice for the smooth completion of road projects $[30,61,62]$.

Studies commissioned by US-NCHRP and State of Indiana to minimize costs and delays associated with utility relocations proposed CCC among stakeholders for the timely and effective utility relocation $[3,28]$. Another study summarized the results of studies conducted by the Local Road Research Board that aimed at developing methods to facilitate efficient utility relocation in Minnesota [58]. A conclusion was made that communication and coordination were the two significant factors that needed to be focused upon to reduce future delays related to utility relocations. Studies commissioned by United States - Federal Highway Administration for the International Technology Exchange Programs also identified CCC as the approved practice implemented in most European countries [63]. In general, early and continuous CCC through the life of a project is the most effective tool to identify \& resolve issues as early as possible, eliminate arbitrary \& unnecessary utility relocations, minimize costly unexpected issues, and facilitate timely utility relocations. 


\subsubsection{Guidelines for Utility Construction within a Road Right of Way}

Developing processes for the management, installation, relocation \& maintenance of utilities is mandatory for the effective management of utilities during road construction projects. This in turn leads for the requirement of utility $\mathrm{CCC}$, accommodation, installation, relocation, and maintenance standard guidelines. Numerous guidelines have been developed for the management, accommodation, relocation and maintenance of utilities within a road reserve.

CCC involves, long-range construction schedules, cooperative working relationships, holding regular meetings with utility owners during planning, design \& construction, and becoming knowledgeable of utility relocation processes \& challenges. Procedures for these activities are provided in utilities CCC guidelines [54, 64-71]. These guidelines describe procedures for the effective $\mathrm{CCC}$ of tasks done jointly by stakeholders. For instance, during planning \& design phases the designer, utility coordinator and utility owners should work together to identify utilities in the existing corridor and create the most conflict avoiding alignment base plan. After commencement of the project the contractor, utility owners and utility coordinator should hold utility relocation meetings, and relocate utilities prior to construction \& during construction of the project.

The guidelines for the accommodation of utilities in road ROW state methods for the placement and installation of new underground pipelines, underground telecommunication wire line, overhead electric power, and communication lines. Most of the guidelines illustrate details on the standard procedures of permitting for utility works, utility design, location, method of installation, adjustment, liability, and conformance standards [57, 71-77]. Furthermore, the Transport Association of Canada guideline for underground utility installation illustrates safety procedures for utility installation works [77]. Procedures for positioning and color coding of underground utilities are also described in the National Joint Utilities Group manual [78].

Utilities relocation should be done with great care; since it involves removal, temporary or permanent relocation/ adjustment and finally installation of existing utilities. Legal requirements and standards for the construction, material quality, and safety are provided in most utility relocation guidelines; in order to prevent service disruptions, damage to utility facilities, hazardous conditions, and ensure timely accomplishment of utility work. Summary of these guidelines [59, 64, 65, 79-82] shall be as follows.

a) Roles and responsibilities of each stakeholder,

b) Procedures to avoid utility conflicts as much as possible during design,

c) Procedures to coordinate utility adjustment work as early as possible,

d) Preparation of utility plans,

e) Preparation of utility relocation cost estimates,

f) Standards for the construction of utilities,

g) Utility adjustment procedures (i.e. techniques for excavation, utility material approval, damage prevention),

h) Procedures for inspection by utility coordinator,

i) Post utility construction activities.

There are different guidelines that establish procedures for clear, consistent pavement repair for street cuts; in order to preserve the original investment of streets [12, 13, 83, 84]. These documents ensure that entities which cut and excavate pavements have the knowledge, competence and resources needed to perform the type and size of work for which they are permitted to perform. The guidelines cover detailed procedures on the following issues.

a) Pavement cut permitting,

b) Submission of construction drawings and site specific traffic control plan,

c) Non-compliance with permitting requirements and violation of law,

d) Work safety requirements, warning signs of street closure, and precaution to other utilities,

e) Excavation requirements (i.e. width of cut, shape of cut edge),

f) Standard quality of material and restoration works (i.e. type of fill, compaction, asphalt patch works, equipment used for works),

g) Inspection of reinstatement works,

h) Protection and cleaning of storm-water system from construction dirt,

i) Use of steel plate bridges and steel plate standards when backfill cannot be completed within a day,

j) Inspection of ride-ability and grade consistency of patches after completion,

k) And defect liability period after completion of pavement cut repair.

\subsubsection{Design Approaches that Minimize Future Utility Relocation}

The need for relocations could be eliminated by acquisition of a separate ROW for utilities [54]. When ROW is acquired for utilities, specific locations near the ROW line may be assigned for each utility. Nevertheless, good road design must find ways to balance the many interests that compete for limited horizontal or vertical space. Utility corridors and undergrounding are among the common practices that maximize the use of available land and eliminate road openings.

Utility Corridors are longitudinal strips of road ROW exclusively for the location of utility facilities; where buried facilities share a joint trench or utilize pipe or box culvert structures $[63,85]$. Undergrounding is a costly process of converting existing overhead utility facilities to underground for accommodation, aesthetic or safety reasons [61, 86]. However, according to the study made on utility owners in Auburn, United States, underground lines are much more expensive; and customers would be paying more if a utility has to bear this cost and pass it through to its customers [87].

With the ever-increasing cost and time required for relocation; leaving utilities in place and designing the road to avoid utility conflicts would eliminate the need to relocate many utility facilities $[87,88]$. Even when utilities are relocated on or before a 
scheduled time and there are no unexpected delays, the work is often very costly and time consuming. It is therefore in the best interest of all stakeholders, if there is no need to relocate at least major utilities in the first place. Utility owners and design consultants can significantly impact project delivery by seriously considering utilities during the design of highway projects. For instance, Germany tries to avoid the need to relocate utilities during highway construction through design measures [63].

Abandoned or out-of-Service utilities should be identified and removed early in the design stage; so that major delay during construction to identify, remove, or seal the facility is eliminated $[3$, 54]. This would benefit utility relocation efforts by eliminating misinformation regarding utilities in highway plans, and increasing space for highway project features or utilities.

Providing training to designers, managers and consultants is helpful practice; because many personnel are not sufficiently knowledgeable of the utility relocation process especially on technical issues, and utility coordination process [89]. Training avoids utility decision-making positions of inexperienced personnel without proper knowledge. Preparing adequate standard guidelines, and ensuring that they do not conflict with each other is also mandatory for successful utility management.

\subsubsection{Methods to Expedite Utility Relocations as Part of Road Construction Project}

Ellis R. conducted a research to develop practical solutions of utility relocation concerns in the state of Florida, US [90]. He suggested that making the contractor responsible for coordinating activities, meetings, and schedules, for locating utilities, and for delays caused by utility relocations as the best solution. This gives a firm motivation to do a thorough and high quality job on the project. Similarly, UK uses design-build practice for utility relocations [63].

Scott C. P. suggests that performing as much utility relocation in advance of construction as possible allows for the project to proceed smoothly [3]. However, excavation for utility relocations should be done safely; in order to avoid risks of damage to utilities. Safe excavation techniques proposed by the Association of Australian Dial-Before-You-Dig Services include the 4P's; Planning, Potholing to establish exact location of utilities, Protecting and supporting exposed infrastructures, and Proceeding with the excavation [60]. Similarly, the United States Occupation Safety and Health Administration provides procedures to avoid hitting underground utility lines during excavation [91].

Moreover, the Washington's New Underground Utility Damage Prevention Act, states excavator responsibilities to report \& mark excavation area, and utility owner responsibilities to mark facilities within the public ROW [92]. According to the statute any scrapes, gouges, cracks, dents, or other visible damage to a utility, or other external protection of underground utility shall be penalized by not more than $\$ 1000$ per initial violation, and not more than $\$ 5000$ per subsequent violation with in a three-year period.

Utility coordination on construction projects has been almost non-existent but is becoming more necessary.
Consequently, it has become recognized that utility coordinators are needed both during the preconstruction and construction stages of nearly all major highway projects [3]. According to the Transportation Association of Canada Guidelines for the Coordination of Utility Relocations, the utility coordinator on a project team is responsible for guidance, approval and coordination of utility relocations at all stages (Planning, design, construction and close out) of road project delivery [68].

\subsubsection{Utility Cut Management during Service Life of Pavement}

Nichols, Vallerga \& Associates studied the impact of excavation due to utility repair on San Francisco streets [93]. They found out that street cuts caused unavoidable damage to the pavement layers and soil supporting the pavement around the perimeter of the utility cut. Summaries by Shahin \& Associates Pavement Engineering on the results of utility cut patching studies conducted in Burlington, Los Angeles, San Francisco, \& Sacramento cities; also presented that utility cuts caused discontinuity in the pavement structure, loss of strength within the adjacent pavement, and decreased pavement performance [94]. Similarly, Charles evaluated damage caused to road structural pavements by utility service providers in Kampala city in 2008; and concluded that reduction in road service life \& serviceability, increased maintenance costs, and unnecessary traffic jams were the effects of utility cut distresses. Currently, utility cuts are managed by a means of recovering surface restoration fees and pavement degradation fees.

Surface restoration fee has historically existed in the road construction standard specifications. This fee is charged where roads that are cut have a poor condition; or where resurfacing the impacted area affects the ride quality, and is not restored back to pre-cut condition [95].

According to the studies conducted in the cities of Burlington, Los Angeles, San Francisco, \& Sacramento, utility patches decreased pavement service life by at least $25 \%$ [95]. Similarly, a forensic investigation conducted to determine the level of impact on the serviceability of pavements in Calgary-Canada due to the utility cuts estimated 22 percent loss of service life [10]. Based on the findings, the City successfully implemented pavement degradation fees to recover costs associated with reduction of service life and any maintenance costs of repairing the long term damage caused by pavement cutting [95]. Similarly, the city of Toronto has also developed sound \& legally defensible pavement degradation fee structure; to tackle with the issues of utility cuts $[96,97]$. According to Transportation Services of Toronto, the pavement degradation fee would ease the future financial burden of costly rehabilitation work as well as recover expenses for review, and inspection of utility cuts [97].

\subsection{Current Trends of Utility Management in Ethiopia}

\subsubsection{Utility Management in the Ethiopian Road Construction Industry}

Construction industry plays a vital role for developing 
countries such as Ethiopia; as they are considerably dependent on the growth and development of their physical infrastructures [98]. Road and utility infrastructures are growing in complexity and size in Ethiopia. According to the 2017/18 annual report of the National Bank of Ethiopia, total road network in Ethiopia has reached 126,773 Km, showing a $5.5 \%$ annual expansion. The report also added that, asphalt road network accounted for about 12.5 percent of the total road network, and telecom density was $43 \%$ [22].

However, both project delays and frequent pavement cuts are problematic in Ethiopia. This is due to the poor construction management practice including the management of utilities. Studies done by Matters M. revealed that the construction management practice in Ethiopia is the second from the last followed by Mozambique [99]. This indicates that the management practice in Ethiopia is even far behind from those poor performing developing countries in Africa. Although Ethiopian literatures about management of utilities during road projects are scarce, there are some indicators of poor utility management practice during design, construction, and post-construction phases of a road project in Ethiopia.

A survey done by Deribachew M., on 86 road projects to assess the reliability of road design practice in Ethiopia, recommended to deeply foresee site conditions and include additional design components during design of road projects [100]. Another indicator that less considerations are given to preventive, conflict avoiding and least impact approaches for utility management during road design stage is the Jima-Chida road project: Feasibility and Environmental Impact Assessment study prepared by the Ethiopian Roads Authority (ERA) [101]. This report proposed compensation for the loss of utility lines as the only mitigation measure for the impact of the road project on utilities. But further studies are required to confirm the gap in utility management practices during road design activities.

Project delays are prominent in the Ethiopian road construction projects. Siraw Y. in his study to identify the factors that cause time overrun on asphalt road construction projects in Addis Ababa city concluded that $80 \%$ of projects suffered time overrun according to their project completion reports [102]. Studies by Koshe and Jha also revealed $91.75 \%$ road projects in Ethiopia have been delayed $352 \%$ of their contractual time [23].

Studies by Temesgen G. to assess the pavement rehabilitation and maintenance practice in Addis Ababa city, confirmed that $44 \%$ of Addis Ababa city roads severely suffer from frequent pavement cuts, and lack of proper maintenance [24]. Another indicator of road repair problems in Ethiopia including Mekelle city is a Dimtsi Weyane TV, March 6, 2019, 9:00 PM television broadcast with a title of 'Mitsgan do Milgab?' The program publicized public complaints due to poor road repair practices in Mekelle, Kedamay Weyane sub-city [103]. Although utility cut is not the only cause for the road damage; this infers that there is a poor utility cut repair practice in Mekelle city.

Yirsaw Z., in his research to identify problem of urban utility infrastructure provision in Bahirdar city, concluded that the urban utility provision is highly constrained by lack of coordination and management during planning, installation and maintenance process [104]. According to Yirsaw Z. this resulted in utility conflicts, ignorance of utilities during urban planning, and damage to paved streets. However the study lack enough details as it have addressed the problem broadly through the urban planning aspect. Conversely, utility management issue is most critical during urban road construction projects. Generally, Ethiopia including Mekelle city lack studies related to the issues of utility relocation, management, and maintenance during road construction projects.

\subsubsection{Laws, Regulations \& Standards for Utility Management in Ethiopia}

The Civil Code of Ethiopia allows expropriation of lands for projects of public utility [105]. This permits placement of public utilities in any land including road ROW for the benefit of the public. Likewise, Ethiopian Proclamation No. 455/2005 (Article $5 \& 6$ ) states removal of utility lines by the utility operators before commencement of project upon request and compensation made by the owner [106]. However, this is often not possible when utility relocation is dependent upon the acquisition of ROW, or the construction of a highway element such as utility corridor \& earthwork.

The Federal Democratic Republic of Ethiopia 1994 constitution Art. 40, Number 3, grants Ethiopian citizens the right to ownership of rural and urban land, as well as of all natural resources [107]. However, the Art. 40, No. 8, states that the government may expropriate private property for public purposes subject to payment in advance of compensation commensurate to the value of the property.

Art 1460 of the Civil Code of Ethiopia, Proclamation No. $165 / 1960$, defines expropriation as a proceeding whereby the competent authorities compel an owner (against payment of commensurate compensation in advance) to surrender the ownership of immovable required for public purposes [105]. Articles 1470 - 78 state the procedures of expropriation of land as follows.

a) Art. 1470 - The owner or any person who benefits by the servitude, of an expropriated immovable, shall within one month from having been served with the expropriation order, inform the competent authorities of the amount of compensation they claim.

b) Art. 1471 - Any interested party may, within the period mentioned in Art. 1470, inform the competent authorities that he objects to the compensation being fixed below a specified amount or paid in fraud of his rights.

c) Art. 1472, 73 - Where the competent authorities do not accept the amount of compensation claimed by an interested party, such amount shall be fixed by an arbitration appraisement committee.

d) Art. 1474, 75, 76 - The amount of compensation or the value of land that may be given to replace the expropriated land shall be equal to the amount of the actual damage caused by expropriation. 
e) Art. 1477 - An appeal to the court from decision of the committee shall be made within three months from the decision of the committee.

f) Art. 1478 - Finally states that the competent authorities may not take possession of an expropriated/ immovable, until they have paid the amount of compensation fixed, or until they deposited the amount to which the dispute relates where there is an objection by owner.

The laws and regulations in Ethiopia do not clearly state the rights, obligations and liability of all stakeholders for utility relocation and management activities. Subsequently the law does not enforce utility operators to provide adequate information about their facilities and coordinate in the utility management activities. Furthermore, client and utility operators are not deemed to cooperate during design, construction, operation and maintenance of the project. Generally, no considerations are given to damage of utilities, utility conflict avoidance, and hidden utilities that might be encountered after commencement of project.

Although there is no specific guideline for utility management and relocation during road construction projects; some ERA manuals have lightly considered utilities during route selection, site investigation, road design and quality control processes of road project.

Both the ERA Route Selection and Site Investigation Manuals suggest to identify the presence of existing utility supply infrastructures during the first field surveys in order to prevent expensive repairs of telecommunications and water supply lines [108, 109]. Moreover, in the Part D - Explanatory notes for low volume road design manual, a feasibility study is recommended in order to decide between change of the road alignment or shifting of utility lines; where the proposed road project location interferes with utilities during site investigation stage [110].

Likewise, the Geotechnical \& Drainage design manuals consider the effect of road project on adjacent structures including utilities [17, 111]. Although detail procedures are not provided the importance of continuous coordination and cooperation among organizations during project development phase is also suggested. Relatively, wider design guidelines are provided in the ERA Geometric design manual [16]. These guidelines suggest some notions on the inclusion of utilities during road design, and placement of utilities without enough detail. The ERA Geometric design manual also proposes the installation of subsurface utilities such as electric, telephone cables, and water mains in a common trench or utility corridor [16]. But, studies are required to identify the current practice on the application of utility corridors on site.

The ERA Pavement rehabilitation manual, discusses about the road deformation and poor surface shape caused due to maintenance of damaged water pipes crossing the road [11]. Some suggestions devoid of detailed procedures for treating localized surfacing defects, such as fog spraying, heated aggregate application, and new surfacing are made. This leaves behind especial utility cut maintenance procedures.

The ERA Quality manual for Feasibility studies and design mentions that utilities require works such as protection, relocation, upgrading or replacement [112]. The manual also includes costs of utility relocations in preliminary project costs. However, no procedures are provided to implement and quantify these works. Both ERA Quality manuals on Construction Management \& Maintenance Management [113, 114], do not include utilities as an issue in the construction, maintenance and financial management aspects of a road project.

Regarding utility operators' standards, the Geometric design manual [16] cited that;

a) The 1975 G.C. Ethiopian Electric Light and Power Authority Distribution Manual gives no guidance on the placement of utilities within the road reserve except for overhead clearance of wires.

b) The Addis Ababa Water and Sewerage Authority reports that they install pipes under the sidewalks, or in the road median where the sidewalk is narrow.

c) The Ethiopian Telecommunications Corporation reports that it uses a depth of 1.0-1.2 meters for primary buried cable, and 0.6-0.8 meters for secondary buried cable installations.

Another Ethiopian standard is the Ethiopian Urban Planning Standard prepared by the Ministry of Urban Development \& Construction [115]. Similarly, it states how road and utilities should be placed without providing proper guidelines. Even the utility placement standard conflicts with that of ERA Geometric design manual [16]. The ERA Geometric design manual mentions the use of utility corridors during placement; whereas the Urban Planning standard recommends placement of utilities separately at a certain distance from each other.

Generally, the Ethiopian utility standards abandon procedures for utility work permits, utility design, liability, traffic control, and conformance standard issues. Even the installation procedures lack details on ROW accommodation rules, safety issues, backfill compaction procedures for underground installations, transverse occupancy rules, utility material quality, utility damage prevention, highway clear zone requirements, construction methods etc.

ERA acknowledges, the importance of utilities identification and that utilities may impact a highway improvement project; because they can be a major consideration both in the design and cost of a project [17]. But apart from these few suggestions and recommendations, these standards lack management framework, communication platform, detail methods \& procedures stating roles, responsibilities \& relationships of each stakeholder for the relocation and management of utilities.

\subsection{Gaps in the Existing Literature}

Internationally, mainly in US, Japan, and Europe, utility management is a very well-researched aspect of construction management. However, there are no Ethiopian literatures that studied utility management during all phases of construction project by considering all project stakeholders. Correlation among utility management practices during project initiation, design, construction and operation phases of project is not also 
researched. Although utility lines are the main integral part of the technical infrastructures of road ROW; Ethiopia lacks literatures, regulations, and guidelines on utility relocation \& management practice during urban road construction projects. Consequently, there is a study gap on issues such as;

a) Drawbacks of utility management during urban road construction,

b) Integrated road \& utility design approaches,

c) Preventive, conflict avoiding and least impact utility relocation practices,

d) Stakeholder cooperation, coordination and communication system during road construction projects,

e) Standard guidelines for the accommodation and installation of utilities in road ROW,

f) Standard guidelines for adjustment \& relocation of utilities,

g) Standard guidelines for utility cut \& road degradation management,

\section{Methodology}

\subsection{Research Design}

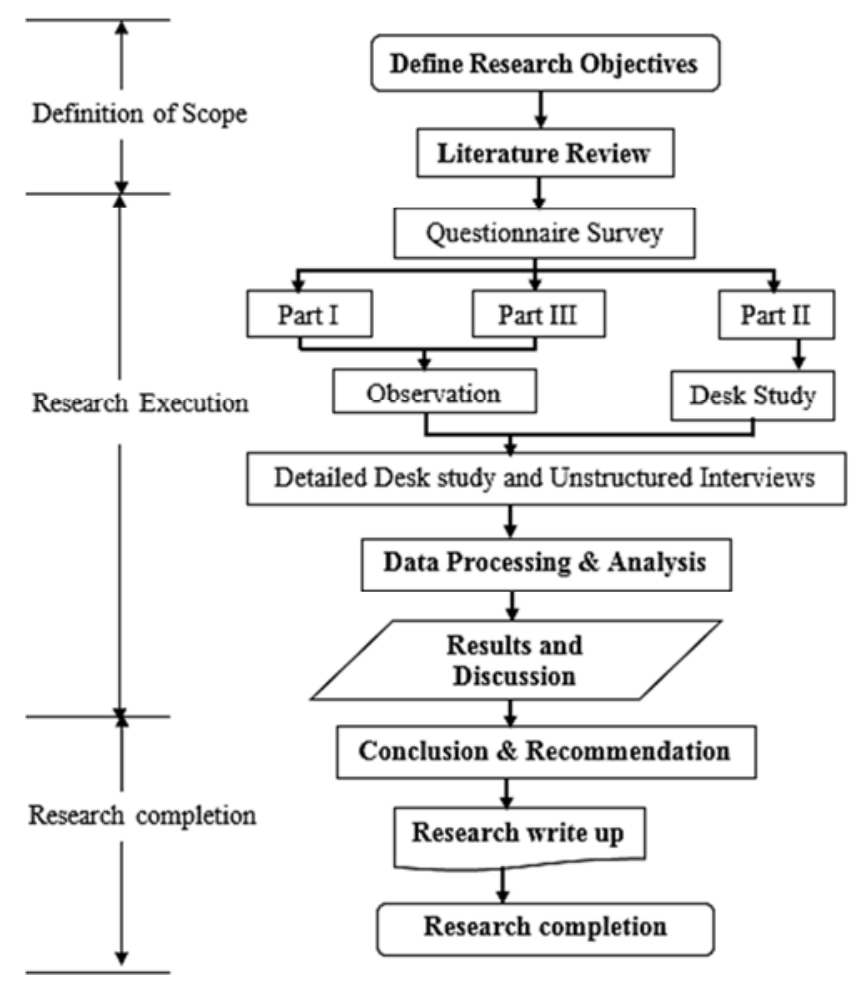

Figure 1. Research Design.

Construction is outcome of project initiation, development, and design stages. Thus to find the root causes of utility management problems all phases of construction project were studied. In addition, all of the project stakeholders were studied; since each of them have got their own share to the utility management problems.

First, quantitative - descriptive - non-experimental cross-sectional - survey approach was used to describe and evaluate the practice of utility management in Mekelle city (objectives $1 \& 2$ ) (Figure 1). Then detailed qualitative case studies on the capacity and limitations of each stakeholders were made in order to identify the root causes of utility management problems (objective 3 ).

\subsection{Part I - Quantitative Research}

Issues of utility management during urban road construction projects arise when there is an upgrading, rehabilitation or reconstruction of existing roads. The way utilities were accommodated and installed in a road ROW during the Pre-construction stage greatly affects requirements of relocation in new road upgrading or rehabilitation works. Similarly, design considerations, construction, and management practices in the on-going project greatly affects the current project itself or future rehabilitation works (Figure 2). In addition, post-construction issues of road repair \& degradation management, and communication among stakeholders during whole project life cycle were also considered.

Thus, the root cause of these issues was studied from two dimensions. The first was the effect of accommodation, installation, and repair practices of existing utilities on the new road construction projects. And the second road-utility design, re-location, construction and management practices in the new road project. Accordingly, both ongoing and recently completed road projects have been studied. In order to avoid the maturation effect due to practical and technological improvements only projects completed over the past 2 years were considered for the study.

Road-utility accommodation, installation, relocation, repair, and management practices are executed according to specific standard guidelines throughout the world. As a result, these practices could be only rated as successful or unsuccessful; since there is no bargaining in safety, quality or economy of a construction practice.

Therefore, a three point semantic differential measurement scale was selected; in order to rate the specific project practices of design, construction, and management as successful, neutral (no response), or unsuccessful on a bipolar basis. In bipolar semantic differential scale, the highest value (1) is assigned to the most desirable response (successful). The less desirable, the lower the value; i.e. (0) for no response, and (-1) for unsuccessful response.

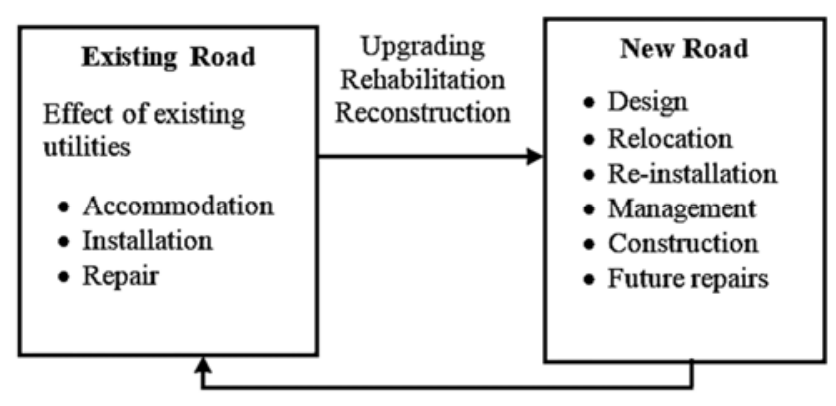

Figure 2. Phases to study utility management issues. 
Based on the review of literatures, 14 parameters were identified in order to measure the effectiveness of utility management practice at the different phases of road construction projects (Table 1). Each of these parameters have got project success criterion that were used to evaluate the utility management practice. Each topic was included in specific questions intended to provide with an understanding of utility management practices and techniques.

The questionnaire was designed based on extensive review of literatures and practice review during urban road construction projects. The questionnaires were divided into three different parts, each one of them addressing one particular area of interest. Part one contained questions designed to study the pre-construction, post-construction and project life utility management practices in already completed road projects. Issues of utility accommodation, installation, repair and management, and the availability standard guidelines, trainings and quality reviews were studied in this survey. The respondents were road administrator, utility operators and urban planners.

Part two and three of the questionnaire surveyed ongoing road construction projects for issues of utility management during road design and construction phases of project. The part two questionnaire provided deep insight in to the effects of design on utility management during urban road construction projects. Issues of integrated road utility mapping, road utility conflict avoidance and other design considerations were surveyed. The respondents were road design consultants of the ongoing projects.

Finally, the part three of the survey studied the construction issues of utility management practice during the construction phase of urban road construction projects. Utility strikes, contract administration, relocation, and re-installation practices were studied. Responses from contractors involved in the sample projects were collected.

The questionnaires were coded according to the variables that they measure. For instance, questionnaires that measure parameter 1 - standard guidelines (Table 1. Project success criterion variables) are coded as $1 \mathrm{a}, 1 \mathrm{~b}, 1 \mathrm{c}$... Similarly for the parameter 2 - knowledge about utilities the questionnaires are coded as $2 \mathrm{a}, 2 \mathrm{~b}, 2 \mathrm{c} \ldots$. Thus, there are 14 groups of questionnaire that measure the 14 variables identified in the table below.

Table 1. Project success criteria variables.

\begin{tabular}{|c|c|c|}
\hline No. & Parameters & Success Criterion \\
\hline \multicolumn{3}{|c|}{ General (Project life) } \\
\hline 1 & Standard guidelines & Existence and adequacy of standards, laws and regulations for utility management in a road ROW. \\
\hline 2 & Knowledge about utilities & $\begin{array}{l}\text { Adequacy of knowledge of designers, builders and managers on utilities, and availability of trainings } \\
\text { programs and mentoring procedures for project staff. }\end{array}$ \\
\hline 3 & Utility information management & Practices for gathering, documentation, sharing, management and retrieval of utility information. \\
\hline 4 & CCC management & Contract administration and stakeholder coordination aspects. \\
\hline 5 & Quality reviews & $\begin{array}{l}\text { Existence of quality reviews to evaluate adequacy of materials, documentation, process, procedures, and } \\
\text { staffing included in execution of works. }\end{array}$ \\
\hline \multicolumn{3}{|c|}{ Pre-construction } \\
\hline 6 & Accommodation & Considerations given to utilities during urban planning, existence of separate ROW for utilities. \\
\hline 7 & Installation & $\begin{array}{l}\text { Subsurface, overhead, longitudinal and cross-sectional utility installation techniques used to avoid future } \\
\text { utility relocations and pavement cutting. }\end{array}$ \\
\hline \multicolumn{3}{|c|}{ Design Phase } \\
\hline 8 & Integrated road utility mapping & $\begin{array}{l}\text { Participation of utility personnel during road design. Considerations given to future utility expansion } \\
\text { works, and to avoid road-utility conflict. }\end{array}$ \\
\hline \multicolumn{3}{|c|}{ Construction Phase } \\
\hline 9 & Contract administration & Existence of compliance and liability clauses about utilities in the contract document. \\
\hline 10 & Relocation \& re-installation & $\begin{array}{l}\text { Existence of utility management and re-installation designs and plans. The practice of utility coordination, } \\
\text { adjustments, and relocation for highway projects. Timely adjustment of utilities. }\end{array}$ \\
\hline 11 & Utility strikes & Safe digging practices, frequency of strikes, loss due to strikes. \\
\hline 12 & Impact of utilities on project & $\begin{array}{l}\text { Delay and disruption caused due to utilities. Reporting and documentation of impacts of utilities on } \\
\text { project. Emergency plans for utility strikes. }\end{array}$ \\
\hline \multicolumn{3}{|c|}{ Post-construction } \\
\hline 13 & Repair & Utility repair techniques and pavement restoration techniques. \\
\hline 14 & Road degradation management & Existence of road degradation fee. \\
\hline
\end{tabular}

Hence, a data collection framework was developed; in order to classify the type of data collected and respondents for each type of questionnaire (figure 3). In order to check the cross-validation of the questionnaire survey data additional data were collected by a means of site observation and desk study.

The sources of data for the questionnaire survey were stakeholders in the Mekelle city road projects (table 2). For the assessment of utility accommodation, installation, and repair practices completed operational roads were studied. Data for this purpose was collected from urban planners, road administrator, and utility operators. Similarly, data for the assessment of utility relocation, re-installation, and management practices was collected from the stakeholders involved in the ongoing road construction projects.

Since each of the utilities in Mekelle city are publicly 
owned and administered under one office there is no difference in practice of utility operators from project to project. Thus part I questionnaire was delivered to all offices to study the practice and general strategy of utility management followed by these organizations. But as the contractor and design consultant differ from project to project part II and part III questionnaires were delivered \& collected from each contractor \& consultant.

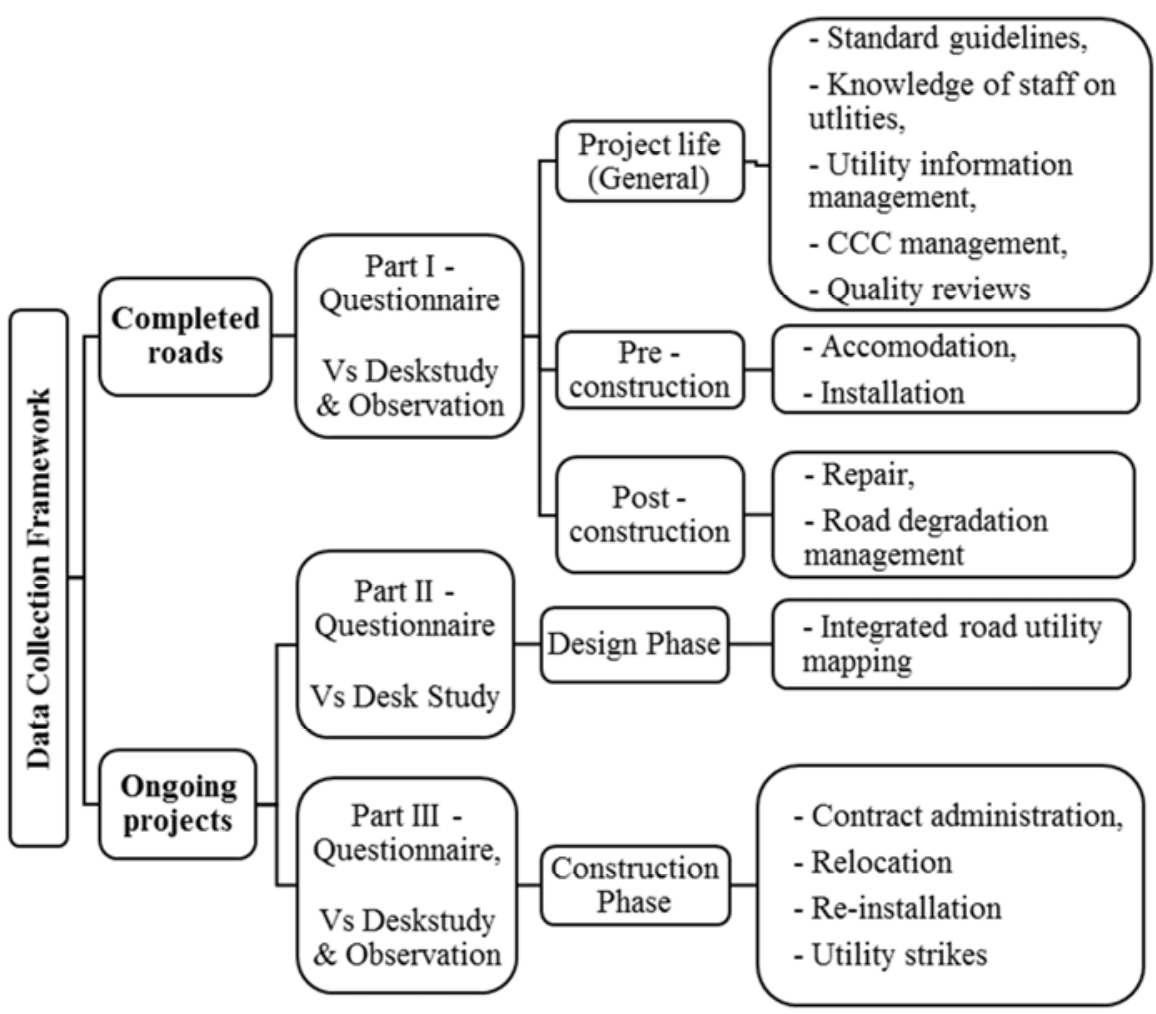

Figure 3. Data Collection Framework.

Table 2. Questionnaire respondents'frequency.

\begin{tabular}{|c|c|c|}
\hline No. & Respondents & Frequency \\
\hline \multicolumn{3}{|c|}{ Part I - Questionnaire survey - Infrastructure office, utility authorities \& urban planners } \\
\hline 1 & Mekelle City Urban Land Information Development Centre & 2 \\
\hline 2 & Mekelle City Infrastructure Office & 1 \\
\hline 3 & Tigray Region Electric Utility Authority - Mekelle Branch Office Design and Relocation team & 2 \\
\hline 4 & Ethiopian Telecommunication Corporation - Mekelle Branch Office Design and Relocation team & 4 \\
\hline 5 & Mekelle Water Supply and Sewerage Services Authority - Design and Relocation team & 1 \\
\hline \multicolumn{3}{|c|}{ Part II - Questionnaire survey - Design consultants } \\
\hline 1 & MU Phase I Project head of Road Design Team & 1 \\
\hline 2 & MU Phase II Project head of Road Design Team & 1 \\
\hline 3 & Sur Construction DB project road design team & 2 \\
\hline 4 & Nomis Engineering & 1 \\
\hline 5 & Net Consults & 1 \\
\hline \multicolumn{3}{|c|}{ Part III - Questionnaire survey - Contractors } \\
\hline 1 & Sur Construction - Phase I Projects Construction managers & 3 \\
\hline 2 & Phase II Projects - Sub-Contractors' Site Engineers (Main Contractor Sur Construction) & 7 \\
\hline 3 & Mekelakeya Construction - Construction Manager & 1 \\
\hline 4 & Yotek Construction - Construction Manager & 1 \\
\hline 5 & Teklebrhan Ambaye - Construction Manager & 1 \\
\hline 6 & CTCE - Construction Manager & 1 \\
\hline 7 & Afrotsion Construction & 1 \\
\hline
\end{tabular}

Thus in order to avoid bias due to organizational culture more experts, from road contracting and consulting organizations that were not partaking in the current road construction projects were included in the sample for the questionnaire survey. Additional measure was also taken to avoid bias by involving more than one expert per organization in the survey when necessary.

\subsection{Part II - Qualitative Research}

After describing the utility management practice in Mekelle city, detailed qualitative case studies were performed in order to identify the root causes of the problems. 
Table 3. Samples of the qualitative study.

\begin{tabular}{|c|c|c|}
\hline No & Organization & Responsibility \\
\hline 1 & Mekelle City Urban Land Information Development Center & Planning Mekelle city \\
\hline 2 & Mekelle City Infrastructure Office & Client of most ongoing and recently completed road projects in Mekelle city \\
\hline 3 & The Legal System & Expropriation of Private Land for Road ROW \\
\hline 4 & Ethiopian Telecommunication Corporation - Mekelle Branch Office & $\begin{array}{l}\text { Operation and administration of optical fiber and copper } \\
\text { telecommunication cables }\end{array}$ \\
\hline 5 & The Tigray Region Electric Utility Authority-Mekelle Branch Office & $\begin{array}{l}\text { Installation, relocation and maintenance of Electric Power utilities in a } \\
\text { road ROW }\end{array}$ \\
\hline 6 & Mekelle Water Supply \& Sewerage Services & Water supply distribution and sewerage disposal services \\
\hline 7 & Road Design Consultants & Design road construction projects \\
\hline 8 & Contractors & Construct roads \\
\hline 9 & Federal Integrated Infrastructure Development \& Coordinating Agency & Design, delivery and management of integrated infrastructures in Ethiopia \\
\hline
\end{tabular}

This answers the question 'Why is there a poor practice of utility management among stakeholders in Mekelle city?'. The performance, capacity and limitations of each stakeholders were studied by evaluating the current practice using the existing Ethiopian laws and guidelines for utility management.

The data for the qualitative case studies were collected by using desk study and unstructured interviews. The samples for the qualitative case study were stakeholders involved in infrastructure planning, construction, and management in Mekelle city (table 3 ). They were selected purposively by considering their contribution to the utility management issues.

\section{Results and Discussion}

\subsection{Results of Quantitative Study}

\subsubsection{The General Practice of Utility Management}

$80 \%$ of the infrastructure planners in Mekelle city have got inadequate or nonexistent standard guidelines. The Ethiopian Telecommunication Corporation, and Mekelle Water Supply \& Sewerage Services lack utility placement, installation, relocation, repair and management guidelines. The Tigray Region Electric Utility Authority uses an outdated manual that gives no guidance on the placement, installation, relocation and management of electric utilities. Mekelle City Urban Land Information Development Center also utilizes an outdated urban planning standard that requires a very large ROW for the accommodation of utilities.

$80 \%$ of the urban planners, utility operators, builders and managers in Mekelle city are not sufficiently knowledgeable of the technical and managerial aspects of utility management. The reasons behind are absence of special trainings, curriculum, and literatures that leverage the utility management body of knowledge.

There are inaccurate, incomplete, and/ or out-of-date information on the existence and location of utilities; as a result of improper utility information collection, depiction, storage, retrieval, updating and sharing practices in $100 \%$ of the infrastructure planners in Mekelle city. Subsurface utility information are inaccurately collected by referring to a mark stone or warning signs. The existing data lacks accurate coordinates of utilities since it is depicted using Computer
Aided Design (AutoCAD) or cartographic mapping techniques. The organizations also lack database or server.

Thus data is stored in personal computers of the planners; which makes it liable to damage and loss. There is almost never a composite map of utilities; because records are seldom put in a single file and are often lost. Besides, there is no system in place to track utility location changes. Thus utilities need to be completely remapped for every new project. The cartographic utility documentation system also makes it difficult to edit and update the existing data. Moreover, the bureaucratic, slow, letter based information sharing system does not allow all stakeholders to share information effectively.

The integration and coordination aspects among $91.43 \%$ of the infrastructure administrators and operators in Mekelle city are very poor. The quarterly integrated forum led by the Mekelle City Council is not adequate for the effective integration of infrastructure development works in Mekelle city. As a result, all of the organizations function in a fragmented, self-centered manner. The root causes are;

a) Failure to plan ahead individually by each organization.

b) Bureaucratic and uncoordinated relationship among organizations.

c) The absence of utility coordination committee that enhances CCC among organizations.

There are no integrated quality assurance planning and implementation for infrastructure works in $100 \%$ of the organizations. Each stakeholders also have got a limited individual asset management program to control the location, condition, replacement, and repair of existing utilities.

\subsubsection{Utility Management During Pre-construction Phase}

$95 \%$ of the Mekelle city roads completed in the past two years suffer from inadequate ROW, and road-utility conflicts. There are poor efforts made to avoid future relocations, and pavement cuts. This is because, urban planners fail to provide adequate ROW for basic infrastructure in conformity of urban plans. The root causes behind are;

a) Lack of server, efficient computers, software applications and trained man power.

b) Lack of quality assurance system to check the placement of infrastructure according to the Mekelle city plan.

c) Absence field surveyors that check the placement of infrastructures before they are installed. 
$95 \%$ of the Mekelle city roads completed in the past two years also suffer from a poor, dis-integrated, non-uniform utility installation practice. The overhead utilities lack a separate ROW; while the subsurface utilities are directly buried without any conduit, duct, sleeve, or any type of encasement. Thus, often times the directly buried utilities are damaged inadvertently due to poor location and lack of protection. This is because there are no Ethiopian utility standards that define detail procedures for ROW accommodation, construction methods, safety, backfill \& compaction, transverse occupancy rules, utility material quality, utility damage prevention, highway clear zone requirements, etc.

\subsubsection{Utility Management During the Design Phase}

$75 \%$ of road designers in Mekelle city practice a poor integrated road utility mapping technique. $100 \%$ of the road designers designed the roads according to the Ethiopian standards. The existing Ethiopian road design standards lack procedures for road-utility conflict avoidance and hinder road designers from using the limited urban space effectively. The standards also lack procedures for utility work permits, utility design, liability, traffic control, and conformance rules. In addition, $100 \%$ of the ongoing road construction projects were designed with the belief that utilities can and will be relocated if there is a conflict. This is due to inadequacy of utility information, and lack of cooperation from utility operators.

\subsubsection{Utility Management During the Construction Phase}

According to the desk study survey $100 \%$ of the ongoing road construction projects lack a clear pre-established contract stating roles, responsibilities, and liability of each stakeholder concerning timely relocation, damage prevention, and compensation of utilities. Besides, there are no adequate mitigation measures for utility removal and management issues in the contract documents. This causes poor utility relocation and re-installation practice because there are no compliance and liability rules.

The Mekelle City Infrastructure Office considered 98\% of relocation works in the ongoing projects after commencement construction. The root causes behind are negligence of duties by the office, and absence of planning \& scheduling of utility relocation works. Thus, contractors spent a great deal of time trying to coordinate with the various utility operators who had administrative authority over those facilities. Nevertheless, the tardy utility coordination process did not yield timely and detailed utility operators relocation planning and implementation in all of the ongoing road construction projects.

Besides, individual utility operators failed to relocate their assets in a timely manner due the following internal problems. The Ethiopian Telecommunication Corporation - Mekelle Branch Office is challenged by lack of authorization of the crew at the branch office to perform utility relocation works (i.e. federal administration). The Tigray Region Electric Utility Authority-Mekelle Branch Office fails to manage and relocate its assets in a timely manner because the organization lacks material and machinery for timely relocation of utilities (i.e. federal purchase and distribution of materials). The Mekelle Water Supply \& Sewerage Services also faces poor motivation of staff due to inadequate wages and benefits.
But then again, the failure of the Mekelle City Infrastructure Office to compensate private land owners and secure the road ROW before commencement of construction in $100 \%$ of the ongoing projects obstructed the utility operators to relocate their facilities even during the relocation process. Although lack of planning and preparation by the Mekelle City Infrastructure Office is the main reason for delay in securing road ROW; the legal system in Mekelle city also fails to provide expropriation of private lands for infrastructure projects in a timely manner (i.e. lengthy land compensation process). This is due to appeal caused by over compensating or under compensating estimates of arbitration appraisement committee.

As a result, $78 \%$ of the contractors suffered disruption and delay losses due to incomplete relocation works prior to construction, and lack of coordination by utility operators during construction. Disruption and inefficiencies are caused since machineries are forced to work around non-relocated utilities. $63 \%$ of the contractors were not able to mitigate these losses; since they allocated inadequate time and space for utility relocations in their project schedule.

Due to the poor information on the location of utilities; utility strikes occurred frequently in $43 \%$ of the ongoing road construction projects. All of the utility operators manage utility strikes in a react to crisis management approach. This is not the best approach given to the additional costs of emergency crews and property damage. Thus, there is a significant gap in identifying and protecting utilities during construction.

\subsubsection{Post-Construction Utility Management Practice}

Pavement cuts and utility damages are unavoidable in $75 \%$ of the Mekelle city roads completed in the past 2 years; since existing re-installations and new installation works were not completed during construction phase of the road projects. The fragmented management in the Infrastructure Offices' in Mekelle city also causes for one organization damaging assets of the other. Besides, absence of utility corridors and the direct burial practice of $100 \%$ of the subsurface utilities exacerbates the frequent pavement cuts for utility repair works. The responsible authority for permitting pavement cuts, collecting surface restoration fees, and repairing the pavement cuts is the Mekelle city Infrastructure Office. The general practice of pavement repair is poor which lacks consistency and smoothness. The reason is that there is no specific standard guideline, or a system that ensures the entities which cut and excavate pavements have the knowledge, competence and resources needed to perform pavement repair works.

In addition, other than surface restoration fees, there are no pavement degradation fees to recover costs associated with reduction of service life, and any maintenance costs of repair to the long term damage caused by pavement cutting.

\subsection{Results of Qualitative Case Studies}

\subsubsection{Mekelle City Urban Land Information Development Center}

The Mekelle City Urban Land Information Development Center is responsible authority for Mekelle city urban 
planning. The organization decides road-utility accommodation and placement in the urban land. This is performed upon a permit issued by the organization according to a request letter written by infrastructure office and utility operators for roads and utilities respectively.

The Ethiopian Urban Planning Standard provides the ROW requirement for the placement of utilities [115]. Although the standard is outdated, it is the only standard used by the organization. According to the standard arrangement and minimum horizontal distance between utility lines are as follows (table 4).

Table 4. Minimum horizontal distance between utility lines.

\begin{tabular}{|c|c|c|c|c|c|c|}
\hline Utilities & Water & Sewer & Power line & Telephone & Gas line & Fuel line \\
\hline Water & - & 1.5 & 0.7 & 0.7 & 0.7 & 1.0 \\
\hline Sewer & 1.5 & - & 1.0 & 1.0 & 1.0 & 1.0 \\
\hline Power line & 0.7 & 1.0 & - & 0.5 & 0.5 & 1.0 \\
\hline Telephone & 0.7 & 1.0 & 0.5 & - & 0.5 & 1.0 \\
\hline Gas line & 0.7 & 1.0 & 0.5 & 0.5 & - & 1.0 \\
\hline Fuel line & 1.0 & 1.0 & 1.0 & 1.0 & 1.0 & - \\
\hline
\end{tabular}

* Source: Ethiopian Urban Planning Standard 2012.

Besides, the Ethiopian Urban Planning Proclamation No. $574 / 2008$, states that urban planning should adhere to the following principles [116];

a) Ensuring economical and sustainable use of land,

b) Ascertaining the support of environmental impact assessment study with respect to development projects likely to have major environmental repercussions,

c) Provision of basic infrastructure during land allocation for development in conformity of urban plans.

The Mekelle city Urban Land Information Development Center fails to provide adequate ROW for basic infrastructure during land allocation in conformity of urban plans and according to the Ethiopian urban planning standard. The Mekelle city master plan have not been successful in adequately guiding and controlling the spatial infrastructure development. It could not guide other sector programs as it is challenged due to technological, financial, and technical limitations.

The main challenge of the organization is that it does not have a server, efficient computers, software applications and trained man power that are adequate to plan Mekelle city ahead of infrastructure expansion. GIS mapping technique is not implemented completely; since it is only used for the identification of land use and building heights.

The office tries to assure quality of placement of infrastructures roughly by overlapping Mekelle city plan with Google earth maps after installation of infrastructures. There are no field surveyors that check the placement of infrastructures before they are installed. As a result most roads and utilities are subject of conflicts, and inadequacy of ROW for their placement.

\subsubsection{Mekelle City Infrastructure Office}

The Mekelle City Infrastructure Office is the client of most ongoing and recently completed road projects in Mekelle city. The Proc. No. 455/2005 (Article 5 \& 6) states removal of utility lines by the utility operators before commencement of project upon request and compensation made by the client [106]. In addition, the Ethiopian Protection of Telecommunication \& Electric Power Networks Proclamation No. 464/ 2005, states that any federal and regional administrative body shall have the duty to protect telecommunication and electric power networks in collaboration with the service providers [117].

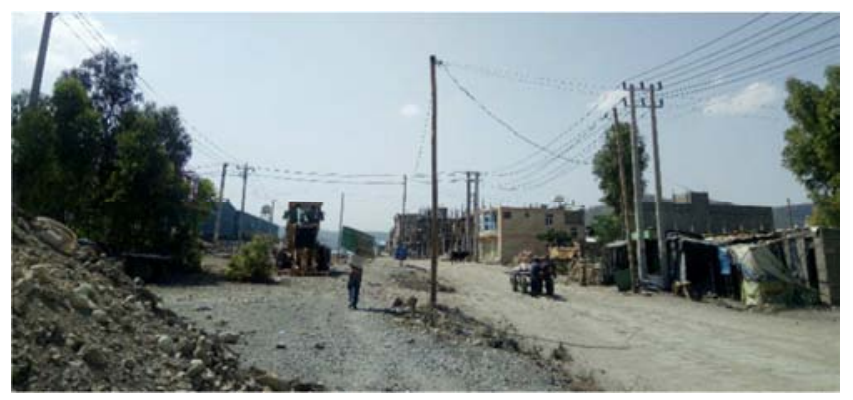

Figure 4. Road ROW that is not secured before commencement of the United Steel Factory (Lachi) to Hamiday Bridge - Messebo Factory Road Project, Mekelle, Ethiopia, May 20, 2019.

However, as a client Mekelle City Infrastructure Office fails to relocate utilities and secure road ROW before commencement of all projects. The office does not compensate private land owners to secure road ROW before commencement of construction. This obstructs the utility operators to relocate the facilities even after construction begins. A good example is the late Dedebit - Da Gebriel Adiha road project which was delayed more than a year due to an appeal of one private land owner on the amount of compensation proposed to secure the road ROW.

Although lack of planning and preparation by the Mekelle City Infrastructure Office is the main reason for delay in compensation of private land and securing road ROW; the other factor is the Ethiopian legal system for expropriation of private land for public purposes.

Even though the legal system was intended to protect the constitutional property right of citizens; it fails to provide expropriation of lands for infrastructure projects in a timely manner. Most of the time appeal occurs as a result of over-compensation or under-compensation of the amount fixed by the arbitration appraisement committee. This makes the process of compensation lengthy. This could have been resolved if there was an item wise, uniform, Mekelle city property valuation document revised every year. Thus, the 
compensation of the property could have been estimated without prejudice by simply calculating the bill of quantity of the property using the already fixed rates.

Besides, priority should have been given to allow infrastructure projects to proceed with their work with a parallel ongoing hearing for private land compensation. This is because, infrastructure projects cause the most costly delay and damage the general benefit of the public. Nevertheless, it could be claimed that the main contributor to these problems to be the Mekelle City Infrastructure Office. This is because the legal system allows to deposit amount of compensation, take possession of immovable, and proceed with public works; where there is an objection made to the compensation in article 1478 (5) of the Civil Code [105].

Another responsibility of the organization is to permit and repair pavement cuts due to utility maintenance works. Nevertheless, the general practice of pavement repair is poor which lacks consistency and smoothness. The organization also manages and cleans storm drains twice a year to prevent flooding of asphalts; since the Mekelle Sanitary \& Beautification Office fails to do so.

\subsubsection{Ethiopian Telecommunication Corporation}

Ethiopian Telecommunication Corporation - Mekelle Branch Office is responsible for the operation and administration of optical fiber and copper telecommunication cables in Mekelle city. The Mekelle branch office have got adequate manpower to perform utility management works during road construction projects. However, the fact that it is federally administered hinders it from performing its works adequately.

The federal administration does not authorize the Mekelle branch crew to design, place and relocate major utility works (i.e. major utility works mean design, placement or relocation of more than 10 telecommunication poles and manholes at a time). This causes for delay of relocation works and direct burial of cables; since it takes at least 3 months for the federal government to design, plan and send its work crew from Addis Ababa.

Most of the time, cables become subject to theft and vandalism since they are not buried quickly due to delay in the arrival of federal crew. For instance, there were 52 cases of optical fiber vandalism in the Zesellsie Square - Elala road project during a 6 month period. This is a serious guilt punishable by 5 to 20 years, according to the Ethiopian Protection of Telecommunication \& Electric Power Networks Proclamation No. 464/ 2005 [117]. This compels for the direct burial of cables in the road ROW which contributes to future pavement cuts. Normally, cables should have been placed in a PVC pipe that connects telecommunication manholes.

Besides, the federally designed telecommunication network exists in a cartographic format in the Mekelle branch office. This makes it impossible to edit and update the maps easily. In addition, the office lacks surveyors and equipment to detect underground utilities. The staffing also lacks trainings for utility relocation, installation and maintenance works. Moreover, the organization lacks standard guideline for installation, relocation and maintenance of its assets.

\subsubsection{The Tigray Region Electric Utility Authority}

The Tigray Region Electric Utility Authority - Mekelle Branch Offices is responsible for the installation, relocation and maintenance of Electric Power utilities in a road ROW. The organization is federally administered but with a greater authorization than the Telecommunication utility operators. They can relocate and maintain existing utilities except for new installations. New installations require a federal authorization since they are federally funded.

The main challenge of the organization is lack material and machinery to relocate utilities in a timely manner. The organization suffers due to lack of material most of the time; since the purchase could only be made federally, and distributed according to the population of the cities without any consideration given to urbanization. In the meantime, Mekelle city is more urbanized. Thus the materials are utilized most of the time before the next federal distribution of materials. Besides, there is only one crane for the installation and relocation of concrete poles in the whole Tigray Region. However, lack of subsurface utility detection instruments is not an issue since most of the power lines are overhead.

The organization have got adequate man power that lack training for the implementation of GIS design. However, it is the only organization with its own guideline as cited in ERA Geometric design manual. It claims that the 1975 G.C. Ethiopian Electric Light and Power Authority Distribution Manual gives no guidance on the placement of utilities within the road reserve, except for overhead clearance of wires [16].

Finally, the Electric utility authority is more challenged than the other utility operators due to lack of ROW during urban road construction projects. This is because it is dangerous for the safety of the public to place high voltage electric utility poles near private dwellings without adequate spacing.

\subsubsection{Mekelle Water Supply \& Sewerage Services}

The Mekelle Water Supply \& Sewerage Services Authority is an organization administered under the Mekelle City Mayor. It is responsible for water supply distribution and sewerage disposal services.

The organization is challenged by lack of trainings for utility planning and design works. Besides, machineries such as back loader, crane, and excavator are lacking for the efficient completion of site works. But, the main challenge of the organization is the lack of motivation of the staff due to inadequate wages and benefits. Most of the site crew claim to work more than an eight hour shift without getting proper benefit for their overtime services.

Mekelle Water Supply \& Sewerage Services Authority have got adequate budget to receive trainings and technology transfer. However, it claims that there is no higher educational institution, such as Mekelle University, that cooperated by providing trainings for the existing manpower. There is no Ethiopian standard that states detail procedures for the design, size, depth, bedding preparation, soil compaction, relocation and maintenance of water and sanitary pipes. The Urban 
Planning standard only states spacing for the horizontal and vertical placement of water and sanitary pipes [115].

\subsubsection{The Challenges of Road Design Consultants}

Mekelle city roads are designed based on the Ethiopian standard guidelines and include utilities in their drawings. However, the Ethiopian Urban planning standard for utility placement is outdated and requires a very large ROW to accommodate utilities. Owing to the poor practice of urban planning, this large ROW is nonexistent in most urban projects or could only be attained through high amount of compensation for private land.

For instance, designed urban road projects to be commenced in the near future, such as Egrimitkal Bridge via Immigration Office to May-Glgalot road project, and Tigray Regional State Administration square road project, have got a ROW width of $18 \mathrm{~m}$ and $15 \mathrm{~m}$ respectively. This totally conflicts with the Ethiopian Urban Planning Standard which states the ROW width for Principal Arterial Streets or Sub Arterial Streets to be $30 \mathrm{~m}$ or only as less as $25 \mathrm{~m}$ where there is an existing built up area [115].

Besides, the guideline does not allow designers to use the limited urban land resource efficiently. Economical techniques such as joint use of poles by electric and telecommunication utilities, and joint use of utility corridors for subsurface utilities could have minimized the ROW requirement in such projects.

In addition, designers are challenged by inaccurate utility data, and uncooperativeness of utility operators during design. Moreover, they could not make considerations for future utility installations that cross the road; since there is no protracted plan of utilities, and it is not known where utilities might cross the road.

Another issue is the limited technical knowledge of designers in the utility relocation process. Utilities occupying a public ROW have increased in number, type, and technical complexity. However, road design engineers and construction contractors have little or no formal training in the technical aspect of utility systems.

\subsubsection{The Challenges of Contractors \& Laws of Utility Strikes}

According to the Ethiopian Energy Proclamation No. 810/ 2013, Article 26, any person who causes damage to any generation, transmission, or distribution facility shall be punished with rigorous imprisonment from five up to fifteen years, or with a fine of up to Birr 50,000 or with both [118].

In addition the Ethiopian Protection of Telecommunication \& Electric Power Networks Proclamation No. 464/2005, Article 3, states that any federal and regional city administrative body shall ensure whether there are telecommunications or electric power networks prior to issuance of construction license and any person who acquired license, shall also guarantee that no damage shall occur on telecommunications or electric power networks [117]. Article 4 of the proclamation also adds that any damage to the utilities is punishable by 6 months to 5 years where such act is committed negligently.
This proclamation makes only the contractor liable to damages that occur to utility assets after getting construction license. However, Mekelle City Infrastructure Office is the real liable authority for most damages of utilities during construction due to failure to relocate and to secure ROW before commencement of project. The law did not provide liability of the client for failure to protect utilities by coordinating with the utility operators. This gap in the law is a very good explanation for the irresponsible acts of the Mekelle City Infrastructure Office and ERA as a client.

The Civil Code of Ethiopia, treats liability due to utility strikes in two forms. These are using laws of contractual liability, if there is a clear pre-established contract; or using a tort law (extra-contractual liability) where there is no pre-established contract [105].

But according to the part III - questionnaire, all of the contractors replied that there is no contractual relationship between contractors and utility operators. According to the desk study, the only clause written concerning utilities in most contract documents between contractors and the road administrator is one stating that the road administrator is responsible for utility relocations.

This generally shows that there is no clear pre-established contract, stating roles, responsibilities, and liability of each stakeholder concerning timely relocation, damage and compensation of utilities. Thus, contractors are the only liable authority according to the Civil Code of Ethiopia. However, the Mekelle City Infrastructure Office should have been liable for not relocating utilities and securing ROW before commencement of construction. Utility operators should have been liable for not relocating utilities in a timely manner. Besides, contractors should have been compensated for delay and disruptions caused due to utility relocation works. Generally, the laws and regulations in Ethiopia does not clearly state the rights, obligations and liability of all stakeholders for utility management during infrastructure construction works.

Utility strikes cost the utility industry as a whole and society in general through interruption of public services, public capital loss due to amendments for punctured public utilities and insurance claims. Utility strikes are the result of out-of-date information, lack of casing/ protection, and absence of utility corridors/ trenches for utilities.

However, the only organization slightly knowledgeable of the damages due to utility strikes is the telecommunication office. The electric and water supply utility operators do not generally report and document their losses due to utility strikes; nevertheless they take the required amount of compensation. The Ethiopian Telecommunication Corporation - Mekelle branch office, reports a 1,767,789.20 Birr costs of repair for snapped subsurface cables during road construction works from February 2018 to January 2019. This excludes losses of litigation, service loss, public capital loss and insurance claims. Detail document of the report is not presented in order to ensure anonymity of the contractors who paid for the damages.

In addition, contractors suffered disruption and delay losses 
due to incomplete relocation works prior to construction, and lack of coordination by utility operators during construction. Disruption is caused since they are forced to work around non-relocated utilities. For instance, the sub-contractor in the Mekelle-Samre road to Abune-Aregawi Lachi Church Project faced a 52,000 birr litigation caused due to telecommunication cable snap.

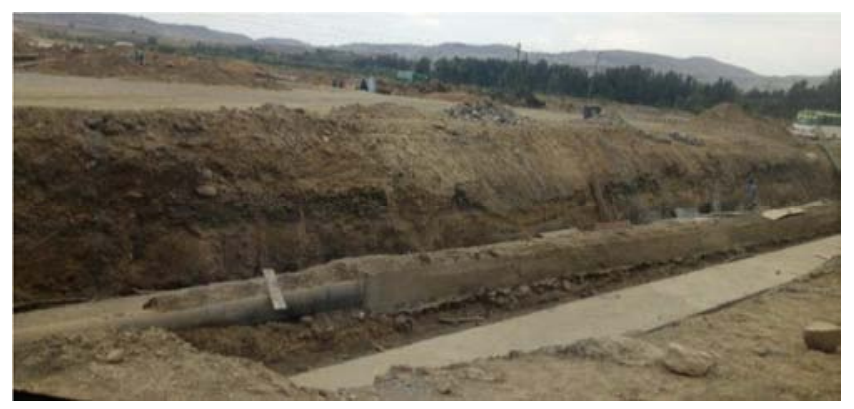

Figure 5. Main water pipe that delayed the Access to Industry Park road project for more than 6 months, Mekelle, Ethiopia, April 15, 2019.

The sub-contractor is also challenged by delays and disruptions due to delayed utility relocation works. Similarly, the sub-contractor in the United Steel Factory (Lachi) to Hamiday Bridge - Messebo Factory Road Project has faced losses of idle crew and machinery due to delayed relocation works.

\subsubsection{Integrated Infrastructure Planning \& Development}

The Ethiopian manual for integrated urban infrastructure \& services planning, was prepared by Ministry of Works and Urban Development in 2006 [119]. This manual provides a road map that guides planners through eight phases of planning, each phase broken down into major tasks and the tasks into activities.

Infrastructure offices' in Mekelle city have got quarterly integrated forum led by Mekelle City Council to discuss and approve long term plans and projects. However, they fail to integrate their long term plans as they fail to plan ahead individually. This lack of planning and integration among infrastructure offices resulted in frequently occurring utility relocations. A very good example is the ongoing MekelleSamre road to Abune-Aregawi Lachi Church road project. This project required the relocation of utilities which were installed two years prior to its commencement of construction.

Most of the organizations characterized their relationship as bureaucratic and uncoordinated. One of the main factors is the lack of standards, laws and regulations stating detail procedures for integrated infrastructure management. The Ethiopian manual for integrated urban infrastructure \& services planning provides a general framework for integration without stating detail procedures, roles, and responsibilities of each organization. Another factor is the absence of utility coordination committee that enhances CCC between organizations. The organizations could have shared their long term plans, and coordinate existing project issues through the coordination committee.

This causes for infrastructure offices to work separately and one damaging assets of the other. Road pavements or pedestrian walkways are frequently cut, and utility operators damage each other's assets; since all relocations and new installations were not complete during construction phase in most projects.

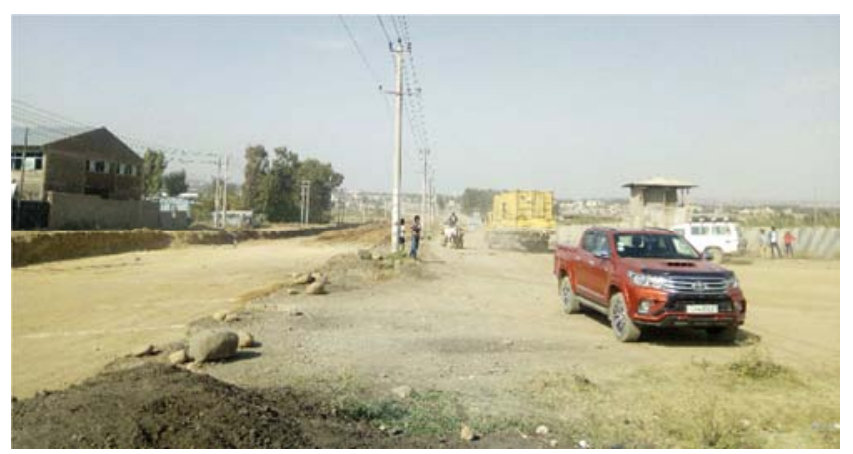

Figure 6. Utilities poorly placed at the center the Mekelle-Samre road to Abune-Aregawi Lachi Church road project 2 years prior to its commencement, Mekelle, Ethiopia, May 31, 2019.

\subsubsection{Federal Integrated Infrastructure Development \& Coordinating Agency}

There is a responsible authority for the design, delivery and management of integrated infrastructures in Ethiopia. The Federal Integrated Infrastructure Development and Coordinating Agency was established under Proclamation No. 857 in August 22, 2014. According to the proclamation, the agency have got the following duties and responsibilities [120].

a) Prepare and submit standards that enable the integration of infrastructure development works to the Council of Ministers for approval.

b) Review policies and laws submitted by the utilities, infrastructure organizations, and urban planners in light of integration of infrastructure development works.

c) Determine codes, designs and color types of signs that identify existing infrastructure works and follow up their compliance.

d) Provide training on integrated infrastructure development works to appropriate organs.

e) Establish technical committees comprising different professionals that enable it to properly discharge its responsibilities.

f) Prepare national integrated infrastructure development works plan and master plan; and necessary support for integrated infrastructure works undertaken by regions.

g) Compile and keep infrastructure data, and provide information to relevant organs upon request.

However, according to the analysis of the questionnaire survey, the agency did not perform its duties and responsibilities. The existing standard guidelines, policies and laws for utility management are inadequate and out of date. Besides, no trainings of integrated infrastructure development are provided by the agency. Furthermore, there are no technical committees comprising different professionals provided by the agency even in the federally funded road construction projects (e.g. Access to Mekelle Industrial Park 
road project). Finally, there is no infrastructure database that is compiled by the agency.

Generally the agency contributes so much to the failure of the utility management practice in Mekelle city; because it fails to direct and guide the general practice of utility management by the infrastructure organizations'. This greatly influences the remaining pre-construction, construction, design, and post-construction practices of utility management.

\subsection{Benchmarking with European and U.S.A. Practices}

The practice of utility management in Mekelle city is very archaic in comparison to the European and U.S.A. approved practices (table 5). Furthermore, the existing resources and locally available technology were not used wisely. This is costing the society a huge waste of public capital.

Table 5. Benchmarking the practice of utility management in Mekelle city.

\begin{tabular}{|c|c|c|c|}
\hline No. & Parameters & Mekelle City & Europe or U.S.A \\
\hline 1 & Standard guidelines & $\begin{array}{l}\text { Utility placement guideline devoid of } \\
\text { detailed procedures }\end{array}$ & $\begin{array}{l}\text { Utility accommodation, installation, relocation, coordination, } \\
\text { repair guidelines }\end{array}$ \\
\hline 2 & Utility information collection & Mark stone and warning signs & Subsurface utility engineering \\
\hline 4 & Utility data storage & Personal computers & Public utility database with its own server \\
\hline 5 & Utility information updating & No way to update paper maps & Better updating practice \\
\hline 7 & Integration and coordination aspects & Self-centred, fragmented & CCC among stakeholders; Utility coordination committee \\
\hline 8 & Quality reviews & Limited asset management program & $\begin{array}{l}\text { Asset management programs, quality assurance planning and } \\
\text { implementation }\end{array}$ \\
\hline 9 & Accommodation & $\begin{array}{l}\text { Road-utility conflicts and inadequate } \\
\text { ROW }\end{array}$ & Placement of utilities in a separate ROW \\
\hline 10 & Installation & $\begin{array}{l}\text { Non-uniform, lacking standard } \\
\text { procedures }\end{array}$ & Based on utility installation guidelines \\
\hline 11 & Integrated road utility mapping & None & $\begin{array}{l}\text { Geo-referenced mapping techniques such as Arc GIS in USA; and } \\
\text { INSPIRE in Europe }\end{array}$ \\
\hline 12 & Relocation \& Re-installation & No procedures & According to utility relocation guidelines \\
\hline 13 & Utility strikes & React to crisis approach & $\begin{array}{l}\text { Preventive approach using safe digging practices, and one-call } \\
\text { notification centre }\end{array}$ \\
\hline 14 & Impact of utilities on project & No consideration & Minimize impact as much as possible during road design \\
\hline 15 & Repair & Lacking consistency and smoothness & According to road repair guidelines \\
\hline 16 & Road degradation management & None & Road degradation fee practices in Seattle \& Canada \\
\hline
\end{tabular}

\section{Conclusion}

This research aimed to evaluate the telecommunication, electric power, and water supply utilities management practice during urban road construction projects in Mekelle city. The practice of utility management was described using a quantitative-descriptive approach; which was followed by qualitative-case studies to identify the root causes of the utility management problems. Finally, evaluation of the practice of utility management in Mekelle city was made by using European and U.S.A. approved practices as a benchmark. Based on the data analysis it is concluded that, the current practice of utility management in Mekelle city during a road project life cycle is very poor both according to the Ethiopian standards, and in comparison to the European and U.S.A. approved practices.

There is improper utility information management practice in all of the infrastructure planners in Mekelle city. As a result, $100 \%$ of the ongoing road construction projects were designed with the belief that utilities can and will be relocated if there is a conflict. In addition, the Mekelle city Infrastructure Office and utility operators failed to complete $98 \%$ utility relocation works in the ongoing projects before commencement of construction. Consequently, $78 \%$ of the contractors suffered disruption and delay losses and $63 \%$ of them were not able to mitigate these losses. However, none of the contractors were reimbursed for their losses due to the lack of a clear pre-established contract for utility relocation works in all of the ongoing projects. Moreover, $43 \%$ of the contractors suffered additional costs of compensation due to frequent utility strikes that resulted from the poor utility information.

Since, there is a poor integration and coordination among $91.43 \%$ of the infrastructure administrators and operators; $95 \%$ of the Mekelle city roads completed in the past two years suffer from inadequacy of ROW, road-utility conflicts, and a poor, dis-integrated, non-uniform utility installation practice. Thus, pavement cuts and utility damages are unavoidable in $75 \%$ of the Mekelle city roads completed in the past 2 years. Nevertheless, the road administrator will not be able to manage costs associated with reduction of service life, and long term damage to the pavements since there is no system to recover those costs.

The root causes to the utility management problems are (1) inadequate or nonexistent standard guidelines, (2) lack of knowledge and technology on the technical and managerial aspects of utility management, (3) absence of integrated infrastructure planning and development, and (4) limited asset management program and quality assurance system among the infrastructure planners and operators in Mekelle city.

The practice of utility management in Mekelle city is very archaic in comparison to the European \& U.S.A. approved 
practices. Furthermore, the existing resources and locally available technology were not used wisely. This is costing the society a huge waste of public capital.

\section{Recommendation}

This section proposes actions that should be taken for the efficient management of utilities during urban road construction projects by considering the local technological and economic limitations in Mekelle city. Construction management is all about using existing scarce resources wisely and effectively by avoiding wastage. Urban land, utility assets, and ongoing \& complete road projects are existing resources with already allocated budget for operation or implementation. Thus the remedial measures recommended below does not require much resources but performance of duties and responsibilities by each stakeholders through a better management practice.

Responsible authorities should prepare utility management policies, laws, standards, and guidelines for the management, accommodation, installation, relocation \& maintenance of utilities. The existing Ethiopian urban planning and road design standards should also be updated to include procedures for the placement, installation, and relocation of utilities in a road ROW. In addition, curriculums and training programs should be held in order to educate the technical and managerial aspects of utility management to the infrastructure planners, builders and managers in Mekelle city.

There must be integrated and proper documentation of the size, location and alignment of utilities. To improve the utility information collection practices subsurface utility detection equipment, filed surveyors, and implementation of subsurface utility engineering are recommended. The organizations should immediately implement 2D GIS based integrated geo-referenced mapping; and consecutively 3D cadaster mapping (i.e. integration of utilities in the urban land tenure system) in the next 1 to 5 years. 2D GIS based mapping is preferred over 3D mapping; since there are sufficient professionals that could provide the training, and two of the organizations are already on the move to implement GIS mapping technique. Data should also be stored safely in a server by creating a city wide centralized utility database to store and archive all as-built utility records. Data distribution should be facilitated through common information sharing platforms such as one-call systems. Creating a common utility coordination committee also enhances the data distribution system among organizations.

An integrated infrastructure management plan should be developed to address all aspects of the interaction among infrastructure offices including the relationships between parties, the legislative and policy context, planning, project development, utility placement, and working in a road ROW. This requires continuous Cooperation, Communication and Coordination (CCC) among stakeholders throughout the life of a project. Road-utility CCC and integration could be facilitated by the establishment of a city-wide utility coordination committee which provides a single-point of contact for project coordination.

Adequate asset management program is mandatory to manage the location, condition, replacement and maintenance of utilities and roads. Quality assurance plan should also be developed to evaluate adequacy of materials, documentation, processes, procedures, and staffing included in execution of works.

The need for relocations could be eliminated by acquisition of adequate ROW for utilities in conformance of the Mekelle city plan. However, for existing utilities, due to the high costs of acquiring new ROW more reliance should be placed on obtaining maximum capacity and usage from existing highway corridors. This requires that emphasis be placed on locating aboveground facilities as far as possible from the traveled way and locating underground facilities where they will not conflict with future road upgrading or rehabilitation works. Utility corridors, and joint use of poles are among the economical practices that maximize the use of available land. Integrated utility installation guidelines should also be developed in order to tackle the poor, disintegrated, non-uniform utility installation practice in Mekelle city.

Designers should include road-utility design analysis and conflict resolution in their design contracts. Since the existing utility information are inaccurate, incomplete, and/ or out-of-date, designers should conduct Quality Level B subsurface utility engineering during design using surface geophysical methods. Better coordination and early engagement of utility operators in the project will also yield timely and detailed utility relocation planning and implementation. Utility operators should provide records of their existing infrastructure, review plans, participate in design meetings, submit relocation plans and schedules, and coordinate their relocation work with the client and designers.

Utility works could be effectively administered by creating contract rules and/ or pursuing legislation that clearly define the roles, responsibilities, and timelines of each stakeholder to hold parties accountable for actions within their control. This creates a reimbursement process between those parties that cause delays and those who lose money as a result. For instance, utility operators will be responsible for all delay costs associated with conflicts if they have identified and not relocated the utilities as per the approved relocation schedules. Or, if they have failed to identify and locate correctly all of the utilities that come in to conflict with construction, they become responsible for associated costs.

Utility relocation and re-installation should be completed before commencement of construction by conforming to the Proclamation No. 455/ 2005 (Art. 5 \& 6) to allow for construction projects to proceed smoothly [106]. Assessing the impacts on utility facilities at the earliest stages of a road project offers the best opportunity to minimize impacts of utilities on project or modify the design in ways that benefit the road project and utility operators.

Utility strikes and conflicts could be managed in a preventive approach when construction plans accurately show the exact location of utilities. Installation of utilities in a common utility corridor, using protection/ casing, and safe digging practices are 
also recommended to minimize utility strikes.

Installation of utilities in a common utility corridor, and placement of utilities in a separate land other than the road ROW also avoids repetitive pavement cutting practice. Besides, standards for street repair works should be developed. Inspection for conformance of pavement repairs and a defect liability period are also recommended. In addition to the surface restoration fee, implementation of pavement degradation fee is also recommended to ease the future financial burden of costly rehabilitation works, as well as recover expenses for review \& inspection of pavement cuts.

There are permitting requirements to proceed with building projects in Ethiopia. However, these requirements are nonexistent for road projects. Thus, responsible authorities should develop a legal document stating conformance rules and permitting requirements for road-utility management practices.

This legal memorandum of understanding among stakeholders should serve as a framework that enforces the necessary collaboration under mutual benefit of all stakeholders. It should state clearly defined procedures, deadlines, responsibilities, and liability of each stakeholder for utility management during urban road construction projects. In addition, permitting procedures by checking conformance with this document should be implemented in the infrastructure development offices.

The clear duties, responsibilities, and conformance rules would halt stakeholders from escaping duties by accusing each other. This guarantees the maximum benefit of all stakeholders. Failure to conform to the legal document would also result in a fair compensation; since there are a clearly defined liability rules.

\section{Acknowledgements}

Above all, glory to the almighty God the Father, God the Son, \& God the Holly Spirit, the creator of heaven and earth, for giving me the gift of life and opportunities out of his purest love. Besides, I owe a very important debt to my family, specially my Mother Teacher Gezu Gebremedhin, for her exceptionally outstanding moral support and encouragement throughout my life.

\section{References}

[1] Quiroga C., Kraus E., Overman J. \& Koncz N. (2015), Integration of Utility and Environmental Activities in the Project Development Process (Report 0-6065-1, Project 0-6065). Texas Transportation Institute, 1-14.

[2] Bell L., Brandenburg S., Ogle J., \& Reinke M. (2014), Evaluation of Utility Relocation Costs \& Best Management Practices. South Carolina Department of Transportation, Columbia, South Carolina, USA.

[3] Scott C. P. (2012), Incentives for utility relocations. National Utilities Liaison, Cardno TBE, 3-9.

[4] Makam K. K. \& Rao C. H. (2015), Time and Cost Overrun Analysis of Highway Projects. Lambert Academic Publishing,
Heinrich Blocking str 6-8, 66121 saarbrucken, Deutschland, Germany, ISBN: 978-3-659-75192-9, 34.

[5] Wijekoon S. B. \& Attanayake A. M. C. T. K. (2011), Study on The Cost Overruns in Road Construction Projects in Sri Lanka. University of Peradeniya \& Sri Lanka Road Development Authority, 7.

[6] Cheyuo V. A. (2016), Impact of Relocating Utility Services During Road Construction: The Management of Issues When They Arise. A Thesis Submitted to The Department of Building Technology, Kwame Nkrumah University of Science \& Technology, Kumasi, Ghana, 57.

[7] Makana L., Metje N., Jefferson I. and Rogers C. (2016), What do Utility Strikes really Cost? A report by the University of Birmingham, School of Civil Engineering, 2.

[8] American Society of Civil Engineers (2002), CI/ASCE 38-02 - Standard Guideline for the Collection and Depiction of Existing Subsurface Utility Data. Reston, VA, 3-8.

[9] Threlfall R. (2018), Smart infrastructure: mapping underground utilities. KPMG International Cooperative, Swiss entity, 3 .

[10] Karim M., Rizvi R., Henderson V., Uzarowski L.; Chyc-Cies, J. (2014), Effect of Utility Cuts on Serviceability of Pavement Assets - A Case Study from the City of Calgary. Paper presented at 2014 Annual Conference of the Transportation Association of Canada, Montreal, Quebec, 15.

[11] Ethiopian Roads Authority (2013), Pavement Rehabilitation \& Asphalt Overlay Design Manual. Federal Democratic Republic of Ethiopia, Addis Ababa, Ethiopia.

[12] Charleston Department of Public Service, (2014), Utility Pavement Cut and Repair Guidelines. City of Charleston Department of Public Service - Engineering Division, 2-15.

[13] Durham Department of Public Works (2009), Street Cut Pavement Repair Standards. Durham City Department of Public Works - Engineering Division, 2-22.

[14] Wu D. \& Zhang X. (2015), A Framework for Effective Management of Underground Utilities. The Hong Kong University of Science and Technology, Journal of Advanced Management Science Vol. 3, No. 3.

[15] KPMG (2018), Smart Infrastructure Mapping Underground Utilities. KPMG, United Kingdom, 3.

[16] Ethiopian Roads Authority (2013), Geometric Design Manual. Federal Democratic Republic of Ethiopia, Addis Ababa, Ethiopia.

[17] Ethiopian Roads Authority (2013), Drainage Design Manual. Federal Democratic Republic of Ethiopia, Addis Ababa, Ethiopia.

[18] Ethiopian Roads Authority (2016), Road Sector Development Program 19 Years Performance Assessment. Federal Democratic Republic of Ethiopia, Addis Ababa, Ethiopia.

[19] Ethiopian Roads Authority (2015), The Road Sector Development Program - Phase V. Federal Democratic Republic of Ethiopia, Addis Ababa, Ethiopia.

[20] National Planning Commission (2016), Growth and Transformation Plan II (GTP II) (2015/16 - 2019/20) Volume I: Main Text. Federal Democratic Republic of Ethiopia, Addis Ababa, Ethiopia. 
[21] International Monetary Fund (2018), World Economic Outlook - Challenges to Steady Growth. International Monetary Fund Publication Services, p - ISSN 0256-6877, e ISSN 1564-5215.

[22] National Bank of Ethiopia (2018), 2017/18 Annual Report. National Bank of Ethiopia, Federal Democratic Republic of Ethiopia, 18 \& 25 .

[23] Koshe W. \& Jha K. N. (2016), Investigating Causes of Construction Delay in Ethiopian Construction Industries. Journal of Civil, Construction and Environmental Engineering, $18-29$.

[24] Temesgen G. (2016), Asphalt Road Pavement Rehabilitation \& Maintenance - Case Study in Addis Ababa City Roads Authority. A thesis submitted to Addis Ababa University, School of Civil \& Environmental Engineering.

[25] Azis A. A., Memon A. H., Rahman I. A., Nagapan S. \& Latif Q. I. (2012), Challenges Faced by Construction Industry in Accomplishing Sustainability Goals. 2012 IEEE Symposium on Business, Engineering and Industrial Applications.

[26] Datta M. (2010), Challenges Facing the Construction Industry in Developing Countries. Department of Architecture \& Building Services, Gaborone, Botswana, 1-10.

[27] Gofori B. D. (2011), Challenges of Construction Industries in Developing Countries: Lessons From Various Countries. Department of Building, National University of Singapore, Singapore, 1-13.

[28] Indiana Department of Transportation (2004), Accountability Communication Coordination \& Cooperation. Report of the Utility Relocation Task Force.

[29] Transportation Association of Canada (2008), Management of Utilities in \& Adjacent to the Public Right-of-Way: Survey of Practices. Transportation Association of Canada, Ottawa, Canada.

[30] Brigman T. L (2005), Utility Owners' Pre-Construction \& Construction Responsibilities. A presentation at the GDOT State Utilities Office, Georgia, USA, 3.

[31] Ellis D. R. \& Thomas H. R. (2003), The root causes of delays in highway construction. Submitted for Presentation at the 82nd Annual Meeting of the Transportation Research Board, Washington, D.C, 13.

[32] South Carolina Department of Transportation (2006), Factors That Delay Active Construction Projects \& Potential Solutions. South Carolina Department of Transportation.

[33] Kraus E., Li Y., Overman J. \& Quiroga C. (2013), Utility Investigation Best Practices \& Effects on TxDOT Highway Improvement Projects. Texas Department of Transportation Research \& Technology Implementation Office, Texas A \& M Transportation Institute, Austin, Texas U.S.A. Report FHWA/TX-13/0=6631-1, 31-153.

[34] Transportation Research Board (March 2012), SHRP 2 Tools for Underground Utility Location, Data Collection, \& Analysis. Strategies for Improving the Project Agreement Process, Transportation Research Board, U.S.A.

[35] Zeiss G. (2014), Geolocating Underground Utility Infrastructure. 3D Infrastructure Reality Capturing Project, City of Las Vegas Main Street. City of Las Vegas, USA.
[36] Environmental System Research Institute (2017), Whatare geometricnetworks?https://desktop.arcgis.com/en/arcmap/10.3 /managedata/geometric-networks/what-are-geometric-network s-.htm.

[37] European Commission Joint Research Centre (2013), D2.8.III. 6 INSPIRE Data Specification on "Utility and Government Services" Technical Guidelines. European Commission Joint Research Centre.

[38] Turkan Y. \& Shane J. S. (2016), Modernizing Road Construction Plans \& Documentation. Local Road Research Board, Minnesota Department of Transportation, St. Paul, Minnesota, U.S.A.

[39] Prakash A. (2017), Geographical Information Systems - An Overview. Indian Institute of Information Technology, 1-6.

[40] Yan J., Jaw S. W., Son R. V., Soon K. H. \& Schrotter G. (2018), Three-Dimensional Data Modelling for Underground Utility Network Mapping. The International Archives of the Photogrammetry, Remote Sensing \& Spatial Information Sciences, Delft, The Netherlands, Vol. XLII-4, 711-715.

[41] Becker, T., Nagel, C. \& Kolbe, T. H. (2011), Integrated 3d modeling of multi-utility networks and their interdependencies for critical infrastructure analysis. In: Advances in 3D GeoInformation Sciences, Springer, 1-20.

[42] Becker T., Nagel C. \& Kolbe T. H. (2013), Semantic 3D Modeling of Multi-utility Networks in Cities for Analysis \& 3D Visualization. 3D GeoInfo Conference, Quebec, Canada, $1-22$.

[43] Hijazi, I., Kutzner, T. \& Kolbe, T. H. (2017) Use Cases and their Requirements on the Semantic Modeling of 3d Supply and Disposal Networks. Kulturelles Erbe erfassen und bewahren-Von der Dokumentation zum virtuellen Rundgang, 37. Wissenschaftlich-Technische Jahrestagung der DGPF, 288-301.

[44] Bazjanac V. \& Crawley D. B. (1997), The Implementation of Industry Foundation Classes in Simulation Tools For The Building Industry, 2-9.

[45] Hashim, M., Wei, J. S. \& Marghany, M. (2010), Subsurface utility mapping for underground cadastral infrastructure. A paper presented in 31st Asian Conference on Remote Sensing (ACRS 2010), 1-5.

[46] Pouliot J. \& Girard P., (2016), 3d Cadastre: With or Without Subsurface Utility Network? 5th International Federation of Surveyors Workshop, Athens, Greece, 1-14.

[47] Steven W. G. (2006), Factors that delay active construction projects and potential solutions. South Carolina Department of Transportation.

[48] Virginia Department of Transportation (2013), Chapter 13 SUE Utility Engineering - Designation and Location. Virginia Department of Transportation, Virginia, USA, 1-7.

[49] British Standards Institute (2014), PAS 128: 2014 Specification for Underground Utility Detection, Verification \& Location. British Standards Institute, London, UK.

[50] Mainroads Western Australia (2018), Underground Utilities Survey Standard 67-08-121. Asset and Geospatial Information Branch Survey and Mapping Section, Mainroads Western Australia, Government of Western Australia, Australia, 9-12. 
[51] Hesham O. \& El-Diraby T. (2005), Subsurface Utility Engineering in Ontario: Challenges \& Opportunities - A Summary of Main Findings. University of Toronto, Department of Civil Engineering, Centre for Information Systems in Infrastructure \& Construction, Toronto, Ontario, Canada, 11.

[52] Sinha S. K., Thomas H. R., Wang M. C. \& Jung Y. J. (2007), Subsurface Utility Engineering Manual. Pennsylvania Transportation Institute, Pennsylvania State University, Pennsylvania, U.S.A., Report PTI 2008-02, 87.

[53] Environmental System Research Institute (2016), Integrating New York City Information Systems - Improving Situational Awareness for Everyone. Esri, 380 New York Street, Redlands, CA 92373 8100, USA, 7-14

[54] Federal Highway Administration (2002), Avoiding Utility Relocations. U.S. Department of Transportation, Publication No. FHWA-IF-02-049, 2.

[55] Li S. \& Cheng H. (2010), Developing a GIS-based Electronic Mark Plant Circulation System in a Collaborative \& End-user Computing Approach. MTR, Hong Kong.

[56] Blue Stakes of Utah Utility Notification Center (2014), Common Ground Alliance - Best Practices. Blue Stakes of Utah Utility Notification Center Inc., 1-5.

[57] Iowa Department of Transportation (2006), Policy for Accommodating Utilities on the County \& City Non-Primary Federal-Aid Road System. Office of Local Systems, Iowa Department of Transportation, Iowa, USA.

[58] Marti M. M., Knutson K. L. \& Corkle J. (2002), Utility Relocation: A Communication \& Coordination Process for Local Governments. Minnesota Local Road Research Board, Minnesota Department of Transportation, St. Paul, Minnesota, USA.

[59] Oregon Department of Transportation (2015), Utility Relocation Guide. Oregon Department of Transportation, Oregon, USA.

[60] Association of Australian Dial before You Dig Services (2019), Dial Before You Dig: User Kit. Victoria, Australia: Australian Association of Dial before You Dig Services Ltd. pp. 6, 21.

[61] American Association of State \& Highway Transportation Officials - Standing Committee on Highways (2004), Right of Way and Utilities Guidelines \& Approved Practices Strategic Plan Strategy 4-4. Highway Subcommittee on Right of Way \& Utilities, Federal Highway Administration, 4 \& 42.

[62] Indiana Department of Transportation (2010), What Lies Within - The Hidden Challenge in Reconstructing Hoosier Highways. Indiana Department of Transportation.

[63] Moeller R., Pestinger J., Frierson M., Kennedy W., McCormick A., Muth C. C., Myers J., Scott P., \&t Waymack S (2002), European Right-of-Way \& Utilities Best Practices. United States Department of Transportation, Federal Highway Administration, Report No. - FHWA-PL-02-013.

[64] Colorado Department of Transportation (2011), Guidelines for Accommodating Utilities in the State Highway Rights of Way. State of Colorado, USA.

[65] Illinois Bureau of Design \& Environment Manual (2007, Chapter Six - Utility Coordination. Illinois Department of Transportation, Illinois, USA.
[66] North Dakota Department of Transportation (2010), Coordination \& Notification for Utility Relocation, Adjustments, \& Reimbursement Policies \& Procedures. North Dakota Department of Transportation. North Dakota, USA.

[67] Oregon Department of Transportation (2007), Procedures for Utility Relocation/ Reimbursement for Federally Funded Local Public Agency Projects. Oregon Department of Transportation, Oregon, USA.

[68] Transportation Association of Canada (2016), Guidelines for the Coordination of Utility Relocations. Transportation Association of Canada, Ottawa, Canada. ISBN 978-1-55187-591-0.

[69] Utah Department of Transportation (2017), Utility Coordination Manual of Instruction. Utah Department of Transportation, Utah, USA.

[70] Wisconsin Department of Transportation (June 2015), WisDOT Guide to Utility Coordination - Chapter 5, Utility Permits \& Chapter 20, Conflicts During Construction. Wisconsin Department of Transportation, Wisconsin, USA.

[71] Washington State Department of Transportation (2014), Standard Specificaitons for Road, Bridge, and Municipal construction 2014 - M 41-10. Washington State Department of Transportation \& American Public Works Association.

[72] North Dakota Department of Transportation (2006), A Policy for Accommodation of Utilities on State Highway Right-of-Way. North Dakota Department of Transportation, Bismarck, North Dakota, USA.

[73] City of Orlando (2009), City of Orlando Engineering Standards Manual. Adopted by City Council, Orlando, Florida, 4th ed.

[74] Kansas Local Technical Assistance Program (2007), Guide for Accommodating Utilities Within Right-of-Way for Counties \& Small Cities in Kansas. Federal Highway Administration, Kansas Department of Transportation, Lawrence, Kansas, USA.

[75] Lincoln-County Highway Department (2016), Accommodation of Utilities on County Highway Right-of-Way. Lincoln County Highway Department, Lincoln, USA.

[76] New Hampshire Department of Transportation (2010), Utility Accommodation Manual. Bureau of Highway Design, New Hampshire, USA.

[77] Transportation Association of Canada (2013), Guidelines for Underground Utility Installations Crossing Highway Rights-of-Way. Transportation Association of Canada, Ottawa, Canada. ISBN 978-1-55187-507-1.

[78] National Joint Utilities Group (2013), NJUG Guidelines on the Positioning \& Color Coding of Underground Utilities' Apparatus. National Joint Utilities Group Ltd. Volume 1, Issue 8.

[79] Pennsylvania Department of Transportation (2018), Design Manual Part 5 Utility Relocation: Gas-Water-Sanitary Sewer-Electric-Telecommunications-Cable Television. Pennsylvania Department of Transportation, Bureau of Project Delivery, Pennsylvania, USA. Publication 16.

[80] Tennessee Department of Transportation (2012), Guidebook for Utility Relocation: Related to TDOT Construction Projects. Tennessee Department of Transportation, Tennessee, USA. $1^{\text {st }}$ ed. 
[81] Virginia Department of Transportation (2016), Utility Manual of Instructions: Utility Relocation Policies \& Procedures. Commonwealth of Virginia Department of Transportation, Virginia, USA. 11th ed.

[82] West Virginia Department of Transportation (2007), Accommodation of Utilities on Highway Right of Way \& Adjustment and Relocation of Utility Facilities on Highway Projects.

[83] Statewide Urban Design \& Specifications (2005), Utility Cut Repair Techniques - Investigation of Improved Cut Repair Techniques to Reduce Settlement in Repaired Areas. Iowa Highway Research Board - Center for Transportation Research \& Education, 131.

[84] Highway Authorities \& Utilities Committee of United Kingdom (2006), Practical Guide to Street Works. The Stationery Office, United Kingdom, London, ISBN-13 978-0-11-552746-3, 9-50.

[85] Clarke R. A. (2008), Designing Major Urban Road Corridors for Active Transportation: The Ottawa Case. A paper prepared for presentation at the Geometric Design in Support of Alternative Transportation Modes Session: of the 2008 Annual Conference of the Transportation Association of Canada, Toronto, Ontario, 14.

[86] Federal Highway Administration (2003), Program Guide: Utility Relocation \& Accommodation on Federal - Aid Highway Projects. Office of Program Administration Federal Highway Administration, U.S.A., 35.

[87] Stokes M. L. (2011), Moving the Lines: The Common Law of Utility Relocation. A thesis submitted to Valparaiso University of Law, ValpoScholar, Vol. 45, No. 2, 485.

[88] Transportation Research Board (2010), NCHRP Synthesis 405 - Utility Location \& Highway Design - A Synthesis of Highway Practice. National Cooperative Highway Research Program, American Association of State Highway \& Transportation Officials, Washington, D.C., USA, 3.

[89] Sturgill R. E., Taylor R. B., Ghorashinezhad S. \& Zhang J. (2015), Methods to Expedite and Streamline Utility Relocations for road Projects (2014 Research Report KTC -14-15/SPR-460-13-1F). University of Kentucky, Kentucky Transportation Center research report, 176 Oliver $\mathrm{H}$. Raymond Building, Lexington, KY 40506-0281.

[90] Ellis R. (2003), Development of Improved Strategies for Avoiding Utility-Related Delays During FDOT Highway Construction Projects. Summary of Final Report, BC 354-52, University of Florida.

[91] Occupational Safety \& Health Administration (2015), Trenching \& Excavation Safety. U.S. Department of Labor Occupational Safety \& Health Administration, U.S.A. OSHA 2226-10R 2015, 4-5.

[92] Washington State (2011), Can You Dig It? - Washington's New Underground Utility Damage Prevention Act. The Washington State, Washington D.C., USA, 1-6.

[93] Nichols, Vallegra \& Associates Pavement \& Materials Engineers (2000), Impact of Utility Cuts on Performance of Seattle Streets. A report submitted to City of Seattle Transportation Office, Seattle, Washington, 44.

[94] Shahin and Associates Pavement Engineering (2002), Analysis of the Impact of Utility Cuts in Rehabilitation Costs in Santa
Cruz County, CA. A report prepared for the County of Santa Cruz, CA, 1-3.

[95] Lakkavalli V., Poon B. \& Dhanoa S. (2015), Challenges in Utility Coordination \& Implementation of Pavement Degradation Fees. Paper prepared for presentation at the Safe Management of Utility Infrastructure within our Roadways Session, 2015 Conference of the Transportation Association of Canada, Charlottetown, PEI, 11.

[96] Mouaket A. \& Capano N. A. (2013), Development of a Pavement Degradation Fee Structure for the City of Toronto. A paper presented at the 2013 Conference of the Transportation Association of Canada, Winnipeg, Manitoba, 14.

[97] Transportation Services of Toronto (2010), Improvements to the Utility Cut Management Process. Staff Report to Public Works \& Infrastructure Committee, Toronto, Canada, 15.

[98] Habenom G. Z. (2017), Research in Ethiopian Construction Industry: Review of Past Studies \& Future Need Assessment. A thesis submitted to Addis Ababa University, School of Civil \& Environmental Engineering.

[99] Matters M. (2014), Manufacturing report 2014. London School of Economics - Center of Economic Performance, London, U.K.

[100] Deribachew M. E. (2016), Reliability Assessment of Design Practice: Road Design Projects in Ethiopia.

[101] Ethiopian Roads Authority (2016), Feasibility \& EIA study, Detailed Engineering Design \& Tender Document Preparation of Jima - Chida Road Project. Federal Democratic Republic of Ethiopia, Addis Ababa, Ethiopia.

[102] Siraw Y. T. (2013), Analysis of Factors Contributing to Time Overruns in Road Construction Projects Under Addis Ababa City Administration. International Journal of Science and Research, e-ISSN: 2319-7064.

[103] Asmelash H., (Writer), \& Angesom B. (Director) (9:00 PM, March 6, 2019), Mitsgan Do Milgab? In Angesom B. (Producers), Tezibti Television Series. Dimtsi Weyane Television, Mekelle, Ethiopia.

[104] Yirsaw Z. (2012), The Problem of Urban Utility Infrastructure Provision in Ethiopia: The Case of Bahir Dar City. MSc. Thesis Presented to Bahir Dar University, School of Urban Design \& Development, Bahir Dar, Ethiopia.

[105] Empire of Ethiopia, (1960), Civil Code of Ethiopia Proclamation No. 165/ 1960 (Art. 1460 - 1488). Federal Democratic Republic of Ethiopia, Addis Ababa, Ethiopia, 258 -259 .

[106] The Federal Democratic Republic of Ethiopia - House of Peoples' Representatives (2005), Expropriation of Landholdings for Public Purposes \& Payment of Compensation Proclamation No. 455/2005. The Federal Democratic Republic of Ethiopia, 3 - 8 .

[107] Federal Democratic Republic of Ethiopia (1994), Constitution of the Federal Democratic Republic of Ethiopia. Federal Democratic Republic of Ethiopia, 13.

[108] Ethiopian Roads Authority (2013), Route Selection Manual. Federal Democratic Republic of Ethiopia, Addis Ababa, Ethiopia. 
[109] Ethiopian Roads Authority (2013), Site Investigation Manual. Federal Democratic Republic of Ethiopia, Addis Ababa, Ethiopia.

[110] Ethiopian Roads Authority (2011), Low Volume Road Design Manual. Federal Democratic Republic of Ethiopia, Addis Ababa, Ethiopia.

[111] Ethiopian Roads Authority (2013), Geotechnical Design Manual. Federal Democratic Republic of Ethiopia, Addis Ababa, Ethiopia.

[112] Ethiopian Roads Authority (2012), Quality Manual - Volume 4 Feasibility Studies \& Design - Part Two. Federal Democratic Republic of Ethiopia, Addis Ababa, Ethiopia.

[113] Ethiopian Roads Authority (2012), Quality Manual - Volume 6A Construction Management (Administration). Federal Democratic Republic of Ethiopia, Addis Ababa, Ethiopia.

[114] Ethiopian Roads Authority (2012), Quality Manual - Volume 7A Maintenance Management (Administration). Federal Democratic Republic of Ethiopia, Addis Ababa, Ethiopia.

[115] Ministry of Urban Development \& Construction - Urban Planning, Sanitation \& Beautification Bureau (2012), Revised Standards for Structure Plan Preparation \& Implementation. Federal Democratic Republic of Ethiopia, Addis Ababa, Ethiopia, $50-54$.
[116] Federal Democratic Republic of Ethiopia- House of Peoples Representatives (2008), Urban Planning Proclamation No. 574/2008. The Federal Democratic Republic of Ethiopia, 10.

[117] The Federal Democratic Republic of Ethiopia - House of Peoples' Representatives (2005), Protection of Telecommunication \& Electric Power Networks Proclamation No. 464/ 2005. The Federal Democratic Republic of Ethiopia, $1-3$.

[118] The Federal Democratic Republic of Ethiopia - House of Peoples' Representatives (2014), Energy Proclamation No. 810/ 2013. The Federal Democratic Republic of Ethiopia, 11 \& 14 .

[119] Ministry of Works \& Urban Development (2006), Integrated Urban Infrastructure \& Services Planning Manual. Federal Urban Planning Institute - Ministry of Works \& Urban Development, $2-65$.

[120] The Federal Democratic Republic of Ethiopia - House of Peoples' Representatives (2014), Proclamation to provide for the Establishment of Federal Integrated Infrastructure Development Coordinating Agency -Proc. No. 857/2014. The Federal Democratic Republic of Ethiopia, 3-5. 